\title{
Hydrogen sulfide attenuates renal I/R-induced activation of the inflammatory response and apoptosis via regulating Nrf2-mediated NLRP3 signaling pathway inhibition
}

\author{
YONGHONG SU ${ }^{1 *}$, YAOQI WANG ${ }^{2,3 *}$, MIN LIU $^{4}$ and HONGGUANG CHEN ${ }^{2,3}$ \\ ${ }^{1}$ Department of Pediatric Surgery, Cangzhou Central Hospital, Cangzhou, Hebei 061001; ${ }^{2}$ Department of Anesthesiology, \\ Tianjin Medical University General Hospital; ${ }^{3}$ Tianjin Research Institute of Anesthesiology, Tianjin 300052; \\ ${ }^{4}$ Department of Urinary Surgery, Cangzhou Central Hospital, Cangzhou, Hebei 061001, P.R. China
}

Received October 23, 2020; Accepted March 23, 2021

DOI: $10.3892 / \mathrm{mmr} .2021 .12157$

\begin{abstract}
Renal ischemia/reperfusion (I/R) injury can lead to acute renal failure, delayed graft function and graft rejection. Nucleotide-binding oligomerization domain NOD-like receptor containing pyrin domain 3 (NLRP3)-mediated inflammation participates in the development of renal injury. Nrf2 accelerates NLRP3 signaling pathway activation and further regulates the inflammatory response. In addition, hydrogen sulfide serves a protective role in renal injury; however, the detailed underlying mechanism remains poorly understood. The present study investigated whether Nrf2 and NLRP3 pathway participate in hydrogen sulfide-regulated renal I/R-induced activation of the inflammatory response and apoptosis. Wild-type and Nrf2-knockout (KO) mice underwent surgery to induce renal I/R via clamping of the bilateral renal pedicles. A total of $20 \mathrm{mg} / \mathrm{kg}$ MCC950 (an NLRP3 inhibitor) was injected intraperitoneally daily for 14 days prior to surgery. Renal tissue and blood were collected from the I/R model mice to analyze NLRP3 and Nrf2 mRNA expression levels, NLRP3, PYD and CARD domain containing, caspase-1, IL-1 $\beta$, Nrf2 and heme oxygenase 1 protein expression levels, cell apoptosis, the secretion of tumor necrosis factor- $\alpha$, IL-1 $\beta$ and IL- 6 cytokines and renal histopathology and function. Renal I/R activated the NLRP3 and Nrf2 signaling pathways. Conversely, MCC950 treatment inhibited
\end{abstract}

Correspondence to: Dr Min Liu, Department of Urinary Surgery, Cangzhou Central Hospital, 16 Xinhuaxi Road, Cangzhou, Hebei 061001, P.R. China

E-mail: 1048276869@qq.com

Dr Hongguang Chen, Department of Anesthesiology, Tianjin Medical University General Hospital, 154 Anshan Road, Tianjin 300052, P.R. China

E-mail: daguang521521@163.com

*Contributed equally

Key words: renal ischemia/reperfusion injury, NLR family pyrin domain containing 3 , Nrf2, hydrogen sulfide, apoptosis activation of the NLRP3 signaling pathway, and prevented I/R-induced renal injury, release of cytokines and apoptosis in renal I/R model mice. Sodium hydrosulfide (NaHS) not only alleviated upregulation of NLRP3 protein expression levels, but also relieved renal injury, release of cytokines and cell apoptosis induced by renal I/R in wild-type mice, but not in Nrf2-KO mice. NaHS alleviated NLRP3 inflammasome activation, renal injury, the inflammatory response and cell apoptosis via the Nrf2 signaling pathway in renal I/R model mice.

\section{Introduction}

Renal ischemia/reperfusion (I/R) is a leading cause of acute kidney injury (AKI) that typically occurs during renal surgery and predisposes individuals to severe dysfunction in multiple organ systems. I/R-induced cell death and inflammation within renal tissue is associated with complex pathophysiological processes and promotes the decline in renal function, thereby leading to the accumulation of metabolic waste product (1). In addition to ischemia-induced renal tissue damage, reperfusion has also been found to trigger a complex pathophysiological cascade that involves excessive release of free radicals and the accumulation of inflammatory cells, subsequently promoting inflammation and further aggravating local ischemia and cellular damage (2).

Subfamilies of the nucleotide-binding domain and leucine-rich repeat containing family serve a key role in the development of the inflammatory response (3). The NLR family pyrin domain containing 3 (NLRP3) inflammasome (previously known as NACHT, LRR and PYD domains-containing protein 3 and cryopirin) is the most characterized inflammasome to date. An increasing number of studies have reported an association between NLRP3 and renal I/R. In AKI, NLRP3 is involved in renal I/R injury (4,5). For example, knockdown of NLRP3 and its adaptor PYD and CARD domain containing (ASC) alleviates I/R-induced renal dysfunction and excessive neutrophil influx into kidney tissue (6). In addition, the knockdown of NLRP3 and/or caspase-1 protects mice from AKI induced by sepsis or lipopolysaccharide $(7,8)$. These findings suggest that the NLPR3 inflammasome may serve a key role in the pathogenesis of renal damage. 
Nrf2 is an endogenous antioxidant gene, located in the cytosol, which combines with Kelch-like ECH-associated protein 1 (Keap). Once activated, Nrf2 is released from Keap and translocates into the nucleus, where it subsequently binds to antioxidant response elements to initiate the transcription of its downstream antioxidant and cytoprotective target genes, such as superoxide dismutase, catalase, glutathione peroxidase, glutathione-S-transferase isozymes, catalytic and modifier subunits of $\gamma$-glutamyl cysteine ligase and NADP(H): Quinone oxidoreductase (9). It was previously reported that Nrf2 is associated with AKI induced by environmental insult, ischemia or xenobiotics (10). Apart from its reported protective role in tissue injury, previous studies have also demonstrated that overexpression of Nrf2 suppresses NLRP3 inflammasome activity and ameliorates tissue injury (11-13). However, the underlying mechanism of the Nrf2 signaling pathway and its effect on NLRP3 inflammasome activation in renal I/R remains unknown.

Hydrogen sulfide $\left(\mathrm{H}_{2} \mathrm{~S}\right)$ has gained recognition for its ability to regulate mammalian homeostasis and fundamental cell processes, such as autophagy (14). A number of studies have reported that $\mathrm{H}_{2} \mathrm{~S}$ serves a protective role against apoptosis, oxidative stress and inflammation in renal injury (15-20). Nevertheless, the underlying protective mechanism of $\mathrm{H}_{2} \mathrm{~S}$ in renal injury induced by $\mathrm{I} / \mathrm{R}$ remains unknown. Therefore, the present study investigated the expression levels of NLRP3 and its adapter, ASC, in renal I/R model mice, and subsequently determined the effect of Nrf2 on NLRP3 expression. The present study also aimed to determine whether $\mathrm{H}_{2} \mathrm{~S}$ protects kidney tissue against renal injury, inflammation and apoptosis via Nrf2-mediated NLRP3 inhibition.

\section{Materials and methods}

Establishment of renal I/R model and treatment groups. A total of 24 male wild-type mice (weight, 20-25 g; age, 6-8 weeks) were obtained from the Laboratory Animal Center of the Academy of Military Medical Sciences (Beijing, China). In addition, nine Nrf2-knockout (KO) male mice (weight, 20-25 g; age, 6-8 weeks) were obtained from Junke Biological Co., Ltd. All animal protocols were approved by the Animal Care and Use Committee of General Hospital of Tianjin Medical University (approval no. IRB2020-DW-04; Tianjin, China), and all efforts were made to minimize animal suffering and the number of animals used. The mice were acclimated to the environment for 3 days prior to the experiment at $22^{\circ} \mathrm{C}$ with $40-60 \%$ humidity, a 12 -h light/dark cycle and free access to water and rodent chow. After mice were anesthetized with intraperitoneal (i.p.) $50 \mathrm{mg} / \mathrm{kg}$ sodium pentobarbital, the bilateral renal pedicles were ligated for 30 min using microaneurysm clamps. Subsequently, the microaneurysm clamps were removed. In the control group, surgery was performed using the same process; however, renal pedicles were not ligated. Following surgery, $0.9 \%$ sodium chloride solution was used to help mice recover. Mice were then sacrificed following reperfusion for $24 \mathrm{~h}$. A total of 24 wild-type mice were randomly divided into the following six groups: i) Control (Con) group $(n=9)$; ii) I/R group $(n=9)$; iii) I/R+MCC950 group ( $n=3)$; and iv) $\mathrm{I} / \mathrm{R}+\mathrm{NaHS}$ group $(\mathrm{n}=3)$. A total of nine Nrf2-KO mice were randomly divided into the following three groups: i) Con group $(n=3)$; ii) I/R group $(n=3)$; and iii) $\mathrm{I} / \mathrm{R}+\mathrm{NaHS}$ group $(\mathrm{n}=3)$.

According to previous research and preliminary experiments (21,22), $20 \mathrm{mg} / \mathrm{kg}$ MCC950 (Sigma-Aldrich; Merck KGaA) was injected (i.p.) daily for 14 days prior to surgery in the I/R+MCC950 group. A total of $50 \mu \mathrm{mol} / \mathrm{kg}$ sodium hydrosulfide [NaHS; i.p.; diluted in normal $(0.9 \%)$ saline; Sigma-Aldrich; Merck KGaA] was injected prior to surgery in the $\mathrm{I} / \mathrm{R}+\mathrm{NaHS}$ group. Once all experimental procedures were complete, mice were sacrificed by cervical dislocation and tissue and blood were collected for subsequent analysis.

Western blotting. Kidney tissue was collected from I/R model mice following $24 \mathrm{~h}$ reperfusion to analyze protein expression levels. Briefly, total and nucleic protein were extracted using RIPA buffer (Thermo Fisher Scientific, Inc.) and protein concentration was determined using a BCA Protein Assay kit (Thermo Fisher Scientific, Inc.). A total of $40 \mu \mathrm{g}$ protein per lane was separated via $10 \%$ SDS-PAGE and transferred onto polyvinylidene difluoride membranes, then blocked with $5 \%$ milk for $2 \mathrm{~h}$ at room temperature. The membranes were subsequently incubated with the following primary antibodies overnight at $4^{\circ} \mathrm{C}$ : Anti-NLRP3 (1:500; cat. no. ab214185; Abcam), anti-ASC (1:200; cat. no. sc-514414; Santa Cruz Biotechnology, Inc.), anti-caspase-1 (1:200; cat. no. sc-56036; Santa Cruz Biotechnology, Inc.), anti-IL-1ß (1:1,000; cat. no. ab200478; Abcam), anti-Nrf2 (1:1,000; cat. no. ab137550; Abcam), anti-heme oxygenase (HO)-1 (1:2,000; cat. no. ab68477; Abcam), anti- $\beta$-actin $(1: 2,000$; cat. no. ab8227; Abcam) and anti-histone H3 (1:2,000; cat. no. ab176842; Abcam). Following primary antibody incubation, the membranes were incubated with the corresponding HRP-conjugated secondary antibodies (1:5,000; cat nos. ab6721 and ab6728; both Abcam) for $1 \mathrm{~h}$ at room temperature. Protein bands were visualized by enhanced chemiluminescence kit (Thermo Fisher Scientific, Inc.) using a Bio-Imaging system (Bio-Rad Laboratories, Inc.) and semi-quantified using Quantity One (V4.6) software (Bio-Rad Laboratories, Inc.). Protein expression levels were normalized to $\beta$-actin for cytoplasmic protein or histone for nucleic protein.

Reverse transcription-quantitative $(R T-q) P C R$. Kidney tissue was collected from I/R model mice following $24 \mathrm{~h}$ reperfusion to analyze mRNA expression levels. Briefly, total RNA was extracted from tissue using TRIzol ${ }^{\circledR}$ reagent (cat. no. 15596026; Invitrogen; Thermo Fisher Scientific, Inc.). Total RNA was reverse transcribed into cDNA using a RevertAid First Strand cDNA Synthesis kit (cat. no. K1621; Thermo Scientific ${ }^{\mathrm{TM}}$; Thermo Fisher Scientific, Inc.) according to the manufacturer's protocol. qPCR was subsequently performed using SYBR PCR Master Mix (Thermo Fisher Scientific, Inc.) on a 7500 Real-Time PCR system (Applied Biosystems; Thermo Fisher Scientific, Inc.). The thermocycling conditions were as follows: Denaturation at $95^{\circ} \mathrm{C}$ for $5 \mathrm{~min} ; 40$ cycles at $95^{\circ} \mathrm{C}$ for $15 \mathrm{sec}$; and extension at $60^{\circ} \mathrm{C}$ for $20 \mathrm{sec}$. The gene-specific primer sequences are listed in Table I. The relative expression levels of the target genes were calculated using the $2^{-\Delta \Delta C q}$ method (23) and normalized to GAPDH expression levels. 
Table I. Primer sequences for reverse transcriptionquantitative PCR.

\begin{tabular}{ll}
\hline Gene & \multicolumn{1}{c}{ Primer sequence $\left(5^{\prime} \rightarrow 3^{\prime}\right)$} \\
\hline Nrf2 & Forward: GTGGTTTAGGGCAGAAGG \\
& Reverse: TCTTTCTTACTCTGCCTCTA \\
NLRP3 & Forward: CCACAGTGTAACTTGCAGAAGC \\
& Reverse: GGTGTGTGAAGTTCTGGTTGG \\
GAPDH & Forward: AAGACCCAGAAATGAAC \\
& Reverse: TCTACACGATAACAACCA
\end{tabular}

NLRP3, NLR family pyrin domain containing 3 .

Immunohistochemistry (IHC). Kidney tissue was collected from I/R model mice following $24 \mathrm{~h}$ reperfusion to determine NLRP3 and Nrf2 expression levels. Briefly, kidney tissue was fixed at room temperature for $48 \mathrm{~h}$ in $10 \%$ formalin, embedded in paraffin and cut into $5 \mu \mathrm{m}$ sections. The sections were subsequently blocked with $5 \%$ milk at $37^{\circ} \mathrm{C}$ for $30 \mathrm{~min}$ and incubated with anti-NLRP3 (1:100; cat. no. ab214185; Abcam) or anti-Nrf2 (1:200; cat. no. ab137550; Abcam) primary antibodies overnight. Following primary antibody incubation, the sections were incubated with HRP-labeled anti-rabbit secondary antibody (1:200; cat. no. ab214880; Abcam) at $37^{\circ} \mathrm{C}$ for $30 \mathrm{~min}$, developed using diaminobenzidine solution for $<3 \mathrm{~min}$ and counterstained with $0.5 \%$ hematoxylin for $3 \mathrm{~min}$ at room temperature. A light microscope was used to visualize IHC staining (magnification, x200; Biorevo BZ-9000; Keyence Corporation).

Renal function assay. A total of 2-3 $\mathrm{ml}$ blood was collected following centrifugation at $3,000 \mathrm{x}$ f for $10 \mathrm{~min}$ at $4^{\circ} \mathrm{C}$ from $\mathrm{I} / \mathrm{R}$ model mice following $24 \mathrm{~h}$ reperfusion. The serum was obtained to analyze renal function via ELISA to determine levels of creatinine (cat. no. C011; Nanjing Jiancheng Bioengineering Institute) and blood urea nitrogen (BUN; cat. no. C013; Nanjing Jiancheng Bioengineering Institute), according to the manufacturer's instructions. Kidney injury molecule-1 (KIM-1) levels in serum were measured by ELISA (cat. no. EK0880; Wuhan Boster Biological Technology Co., Ltd.) according to the manufacturer's instructions.

Hematoxylin and eosin staining. Kidney tissue was collected from I/R model mice following $24 \mathrm{~h}$ reperfusion to evaluate renal histopathological changes. Tissue was fixed at room temperature for $48 \mathrm{~h}$ in $10 \%$ formalin and then embedded in paraffin. Paraffin-embedded sections were cut into $5-\mu \mathrm{m}$ thick sections and stained with $0.5 \%$ hematoxylin for $5 \mathrm{~min}$ and eosin for $3 \mathrm{~min}$ at room temperature $\left(25^{\circ} \mathrm{C}\right)$. The presence of hemorrhage, tubular cell necrosis, tubular dilatation and cytoplasmic vacuole formation in the tissue was scored as follows: 0 , normal kidney; 1 , minimal damage; 2 , moderate damage; and 3, severe damage (24). Renal injury scores were calculated in a blinded manner by two researchers under a light microscope (magnification, x200; Biorevo BZ-9000; Keyence Corporation).
ELISA analysis of TNF- $\alpha, I L-1 \beta$ and IL-6 levels. Blood was collected $(1 \mathrm{ml})$ from I/R model mice following $24 \mathrm{~h}$ reperfusion. The serum was obtained by centrifugation at 3,000 $\mathrm{x} g$ for $10 \mathrm{~min}$ at $4^{\circ} \mathrm{C}$. The serum levels of TNF- $\alpha$ (cat. no. MTA00b), IL-1 $\beta$ (cat. no. MLB00C) and IL-6 (cat. no. M6000B) were analyzed using commercial ELISA kits (R\&D Systems, Inc.), according to the manufacturer's protocol on a microplate reader (cat. no. CA94089; Molecular Devices, LLC).

TUNEL staining. Kidney tissue was collected from I/R model mice following $24 \mathrm{~h}$ reperfusion to evaluate cell apoptosis using TUNEL staining. Briefly, tissue was fixed at room temperature for $48 \mathrm{~h}$ in $10 \%$ formalin, embedded in paraffin and cut into $5-\mu \mathrm{m}$ thick sections. Sections were incubated with TUNEL reagent in a humidified chamber at $37^{\circ} \mathrm{C}$ for $60 \mathrm{~min}$ in the dark (Roche Diagnostics) and stained with DAPI for $5 \mathrm{~min}$ at room temperature. Then, 10 high-power microscope fields were randomly picked and observed in each section with a fluorescence microscope (magnification, x10).

Statistical analysis. Data are presented as the mean \pm SD of three experiments and were analyzed by GraphPad Prism 5 (GraphPad Software, Inc.). Statistical differences between two groups were analyzed using a paired Student's t-test. Statistical differences between more than three groups were analyzed using one-way ANOVA followed by post hoc Tukey's multiple comparisons test. All data were normally distributed and had an equal variance. $\mathrm{P}<0.05$ was considered to indicate a statistically significant difference.

\section{Results}

MCC950 treatment prevents I/R-induced NLRP3 signaling activation following renal injury in mice. The NLRP3 inflammasome pathway is activated and serves a crucial role in kidney injury $(25,26)$. A previous study also reported that NLRP3 signaling is activated in renal tissue of mice at $24 \mathrm{~h}$ post-reperfusion (4). Therefore, $24 \mathrm{~h}$ post-reperfusion was selected as the present assessment time point. NLRP3 protein expression levels were upregulated by renal I/R injury in the I/R group compared with the control (Con) group (Fig. 1A and B). A similar trend was observed in NLRP3 mRNA expression levels (Fig. 1C). Furthermore, the number of NLRP3-positive cells increased in the I/R group compared with the Con group, as determined by IHC staining (Fig. 1D and E).

In order to determine the underlying mechanism of NLRP3 inflammasome activation and the effect on the downstream signaling pathway following renal I/R injury, mice were treated with the NLRP3 inhibitor MCC950. Western blotting results demonstrated that I/R upregulated protein expression levels of NLRP3 and its adaptor ASC and promoted maturation from pro-caspase- 1 to caspase- 1 and pro-IL- $1 \beta$ to and IL- $1 \beta$ in the I/R group compared with the Con group (Fig. 2A-E). These results indicated that renal I/R may induce activation of the NLRP3 inflammasome pathway and treatment with MCC950 may downregulate NLRP3, ASC, caspase-1 and IL-1 $\beta$ expression levels following renal I/R injury.

Effect of the NLRP3 inflammasome on renal injury, inflammation and apoptosis in renal I/R model mice. In order to 
A

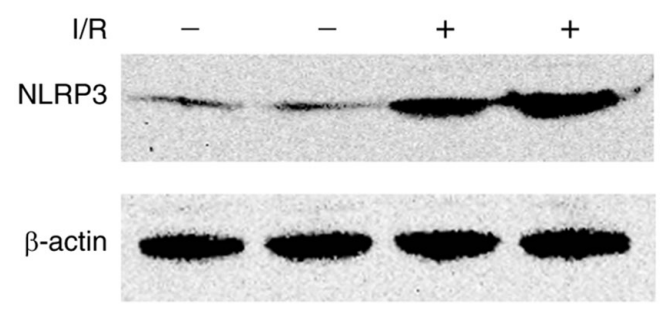

C

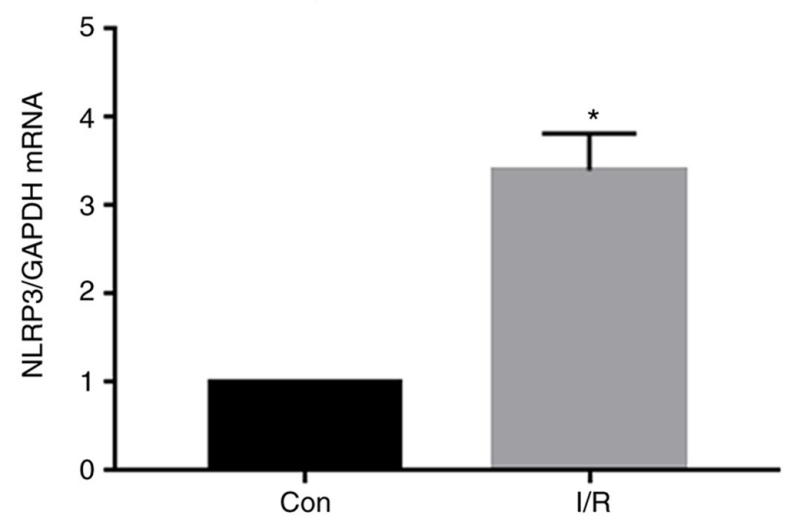

$\mathrm{E}$

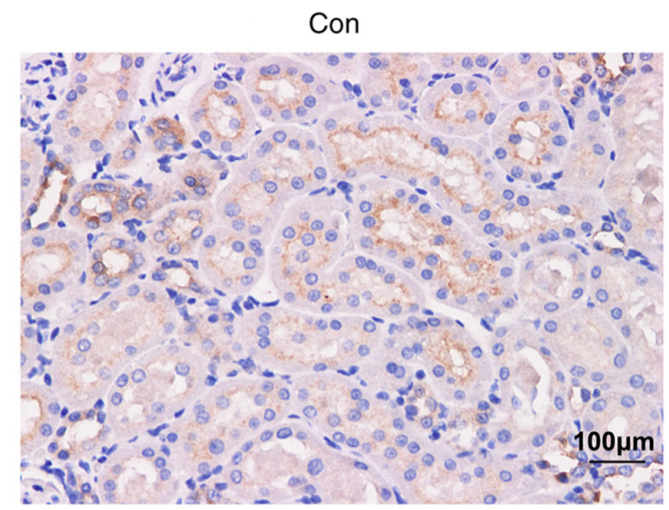

B
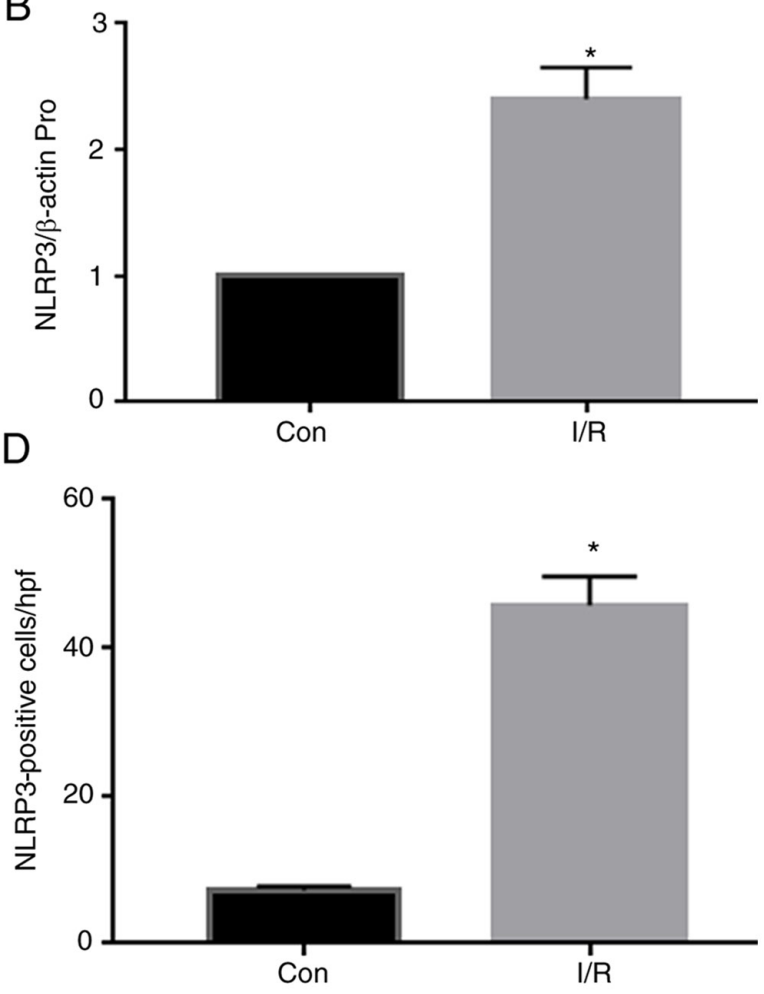

$\mathrm{I} / \mathrm{R}$

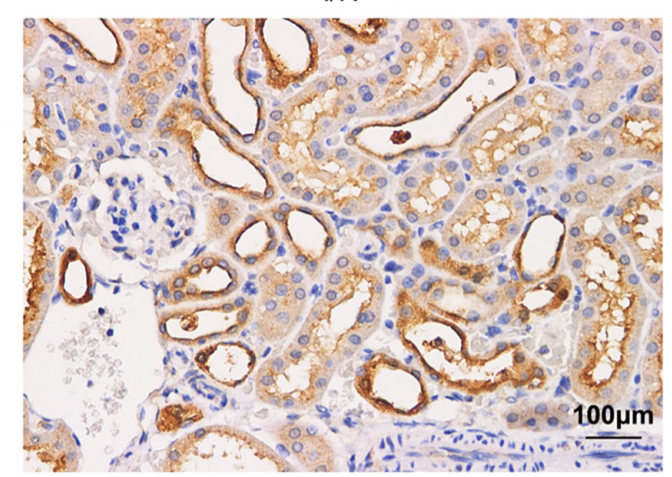

Figure 1. Renal I/R upregulates NLRP3 expression levels. Mice underwent surgery to induce renal I/R via clamping of the bilateral renal pedicles. Following $24 \mathrm{~h}$ reperfusion, renal tissue was collected to analyze NLRP3 protein and mRNA expression levels by (A and B) western blotting, (C) reverse transcription-quantitative PCR and (D and E) immunohistochemistry (scale bar, $100 \mu \mathrm{m})$. Data are presented as the mean \pm SD $(\mathrm{n}=3)$. "P $<0.05$ vs. Con. I/R, ischemia/reperfusion; NLRP3, NLR family pyrin domain containing 3; Con, control.

determine the effect of NLRP3 on renal injury, I/R model mice were treated with the NLRP3 inhibitor MCC950. Renal I/R model mice exhibited significantly increased levels of BUN, serum creatinine and KIM-1, which is a biomarker of renal injury (Fig. 3A-C), indicating successful induction of renal I/R injury. Histological examination of renal tissue from I/R model mice revealed increased histological score, which was evidenced by severe tubular epithelial swelling, tubular dilation and interstitial edema, vacuolar degeneration and loss of the brush border, which suggested that renal I/R may promoted significant renal tissue damage and increased histological score (Fig. 3D and E). Inhibition of NLRP3 by MCC950 treatment significantly decreased I/R-induced increases in BUN, creatinine and KIM-1 levels and decreased histological score, with renal tissue exhibiting fewer severely injured tubules (Fig. 3A-E).
In addition, levels of inflammatory factors and apoptotic cells following MCC950 administration were analyzed in renal I/R model mice. Indicators of inflammation, including TNF- $\alpha$, IL-1 $\beta$ and IL-6, were significantly upregulated in the I/R group compared with the Con group (Fig. 3F-H). Moreover, compared with the Con group, the percentage of apoptotic cells was significantly increased at $24 \mathrm{~h}$ post-reperfusion in the I/R group (Fig. 3I and J). Compared with the I/R group, the secretory levels of cytokines, TNF- $\alpha$, IL- $1 \beta$ and IL- 6 , and the percentage of apoptotic cells were decreased by MCC 950 treatment in the I/R+MCC950 group (Fig. 3F-J). These results indicated that inhibition of the NLRP3 inflammasome may prevent release of inflammatory factors and apoptosis of renal tissue induced by $\mathrm{I} / \mathrm{R}$.

Nrf2 is essential for renal $I / R$-induced regulation of NLRP3 inflammasome activity. A previous study revealed that $\mathrm{Nrf} 2$ is 
A

\section{ALRP3 \\ ASC \\ Pro caspase-1 \\ Caspase-1 P10}

Pro IL-1 $\beta$

$\mathrm{IL}-1 \beta \mathrm{P} 17$

$\beta$-actin

I/R

$\operatorname{MCC} 950$

B

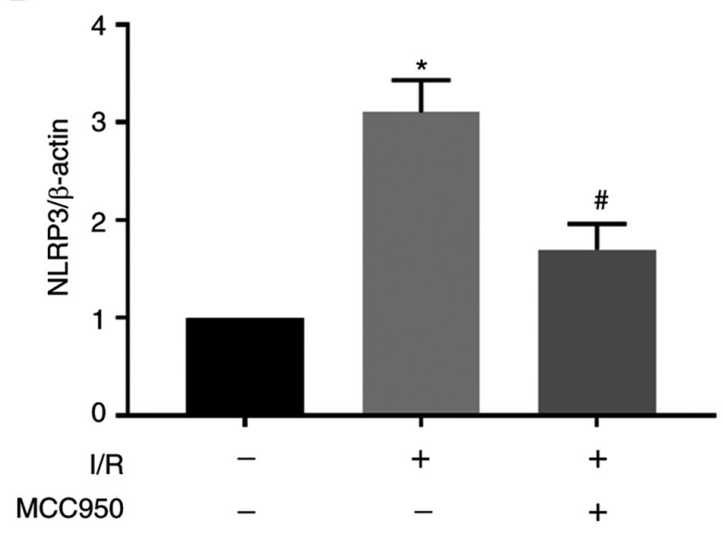

D

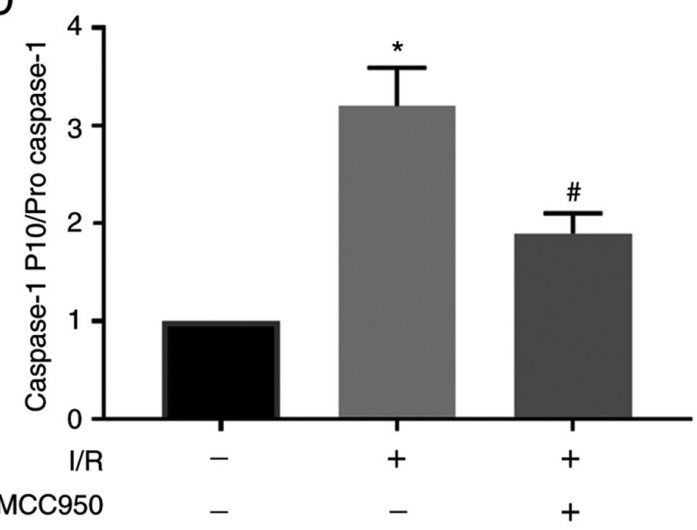

C

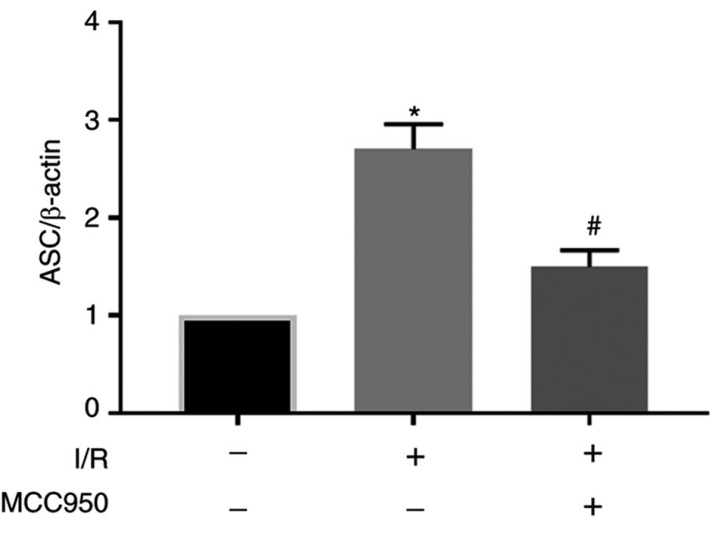

E

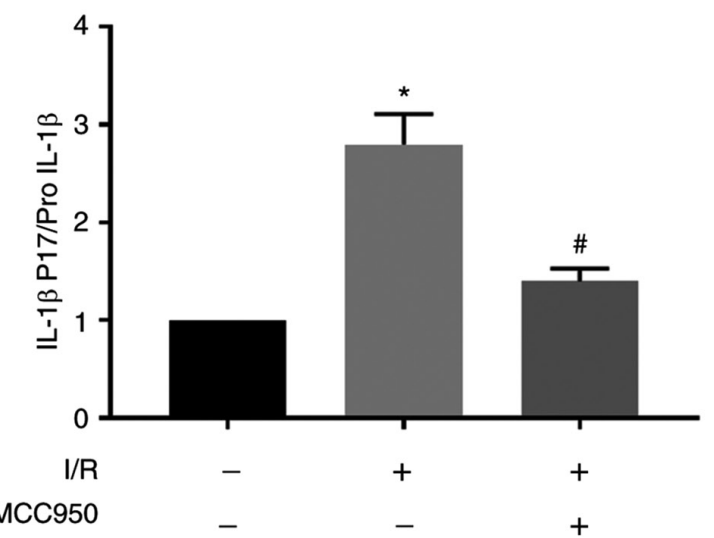

Figure 2. MCC950 downregulates expression levels of NLRP3 signaling pathway-associated proteins following renal I/R. Mice underwent surgery to induce renal I/R via clamping of the bilateral renal pedicles. Mice were injected with $20 \mathrm{mg} / \mathrm{kg}$ MCC 950 intraperitoneally daily for 14 days prior to surgery. Following $24 \mathrm{~h}$ reperfusion, renal tissue was collected for (A) western blot analysis of (B) NLRP3, (C) ASC, (D) caspase-1 and (E) IL-1 $1 \beta$ expression levels. Data are presented as the mean $\pm \mathrm{SD}(\mathrm{n}=3)$. ${ }^{*} \mathrm{P}<0.05$ vs. Con; ${ }^{*} \mathrm{P}<0.05$ vs. I/R. I/R, ischemia/reperfusion; NLRP3, NLR family pyrin domain containing 3; ASC, PYD and CARD domain containing; Con, control.

activated and expression levels of Nrf2 target genes are upregulated in kidney tissue following renal I/R injury (27). Similar findings were obtained in the present research. Nucleic, total protein and mRNA expression levels of Nrf2 were analyzed at $24 \mathrm{~h}$ post renal I/R injury. The results demonstrated that, compared with the Con group, the nucleic, total protein and mRNA expression levels of Nrf2 were upregulated in the I/R group (Fig. 4A-D). In addition, IHC analysis found that expression levels of $\mathrm{Nrf} 2$ in renal tissue were increased, which was demonstrated by increased number of Nrf2-positive 
A

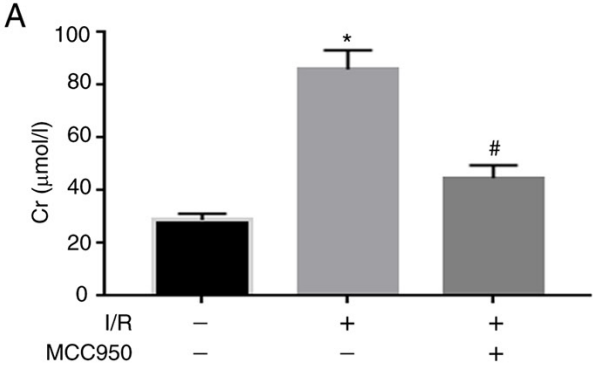

C

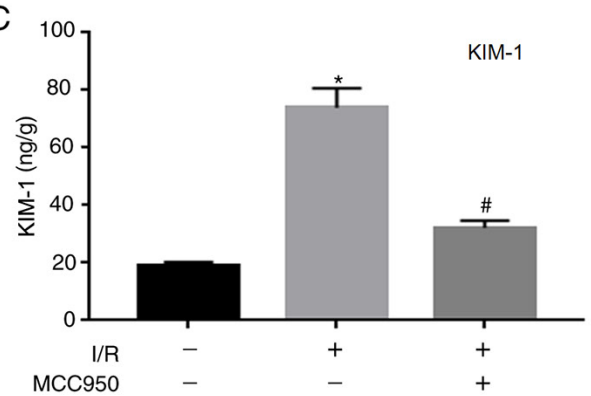

F

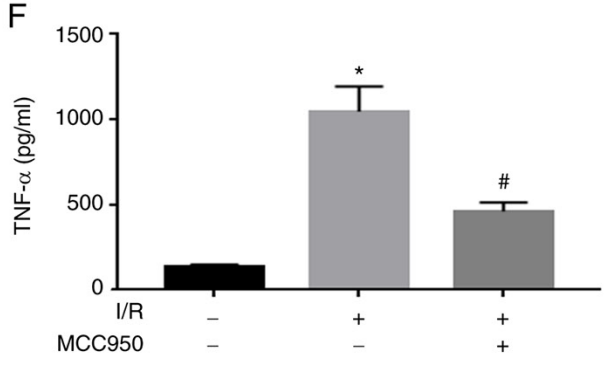

$\mathrm{H}$

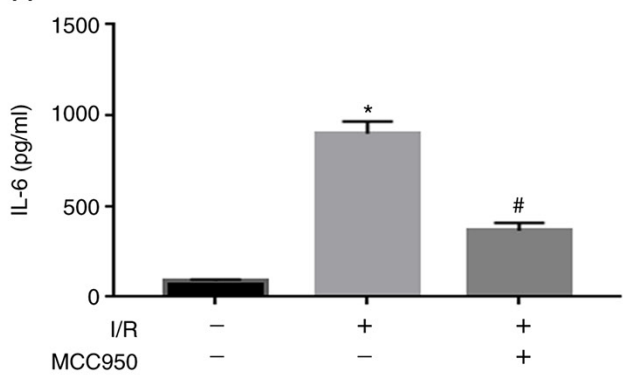

B

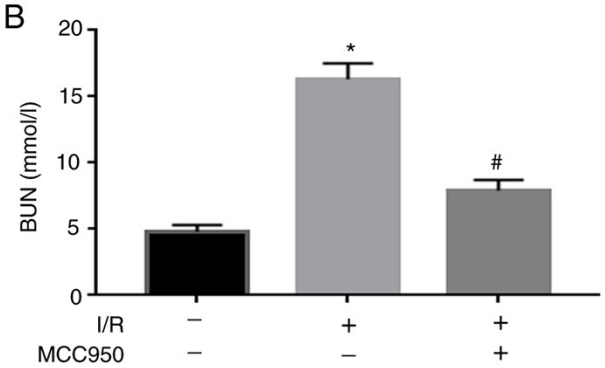

D

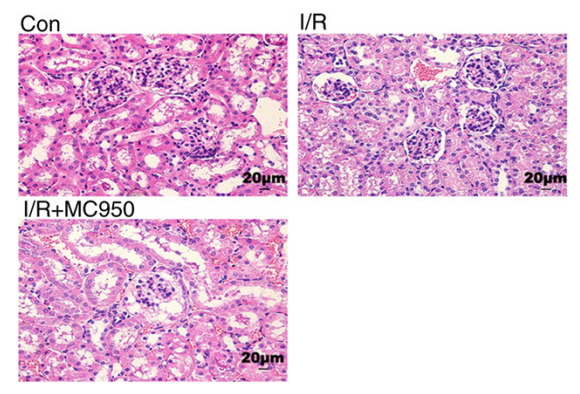

G

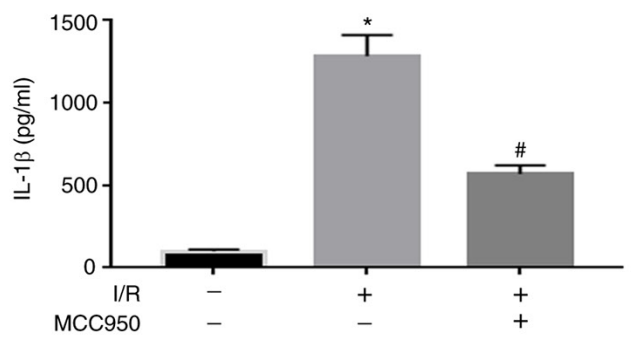

I Con
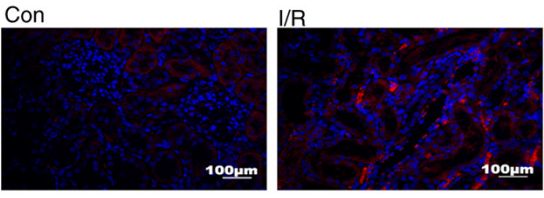

I/R+MCC950

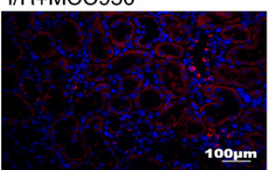

E

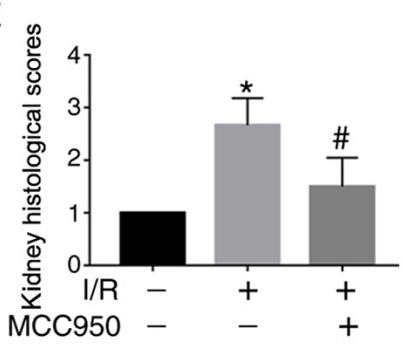

Figure 3. MCC950 alleviates renal function and injury and decreases cytokine levels and apoptosis following renal I/R. Mice underwent surgery to induce renal I/R via clamping of the bilateral renal pedicles. Mice were injected with $20 \mathrm{mg} / \mathrm{kg}$ MCC 950 intraperitoneally daily for 14 days prior to surgery. Following $24 \mathrm{~h}$ reperfusion, renal tissue and blood were collected to analyze (A) Cr, (B) BUN and (C) KIM-1 levels. (D) Histopathological changes were assessed and (E) scored. Scale bar, $20 \mu \mathrm{m}$. (F) TNF- $\alpha$, (G) IL-1 $\beta$ and (H) IL-6 expression levels and (I and J) apoptosis were assessed. Scale bar, $100 \mu \mathrm{m}$. Data are presented as the mean $\pm \mathrm{SD}(\mathrm{n}=3)$. ${ }^{\mathrm{P}}<0.05$ vs. Con; ${ }^{*} \mathrm{P}<0.05$ vs. I/R. I/R, ischemia/reperfusion; Cr, creatinine; BUN, blood urea nitrogen; KIM-1, kidney injury molecule-1; Con, control.

cells observed in the I/R group (Fig. 4E and F). These data suggested that activation of the Nrf2 signaling pathway may initiate a protective response in renal I/R model mice.

In order to verify the effect of Nrf2 on the NLRP3 inflammasome pathway in renal I/R, Nrf2-KO mice were used in subsequent experiments. Protein expression levels of Nrf2 and its target gene, HO-1, were significantly downregulated following renal $\mathrm{I} / \mathrm{R}$ in $\mathrm{KO}$ mice compared with wild-type mice (Fig. 5A-C). Conversely, compared with the I/R wild-type group, the expression levels of NLRP3 and its adaptor, ASC, caspase-1 and IL-1 $\beta$ were upregulated in the
I/R KO group (Fig. 5A and D-G). These data indicated that renal I/R may induce activation of the NLRP3 inflammasome in Nrf2-KO mice.

NaHS alleviates I/R-induced upregulation of NLRP3 protein expression levels in wild-type, but not in Nrf2-KO, mice. NaHS has been demonstrated to exert effects on Nrf2 expression and NLRP3 inflammasome activation in different disease models (28-30). The present study investigated whether the effect of NaHS on activation of the NLRP3 pathway occurs via the Nrf2 signaling pathway by analyzing expression levels 
A
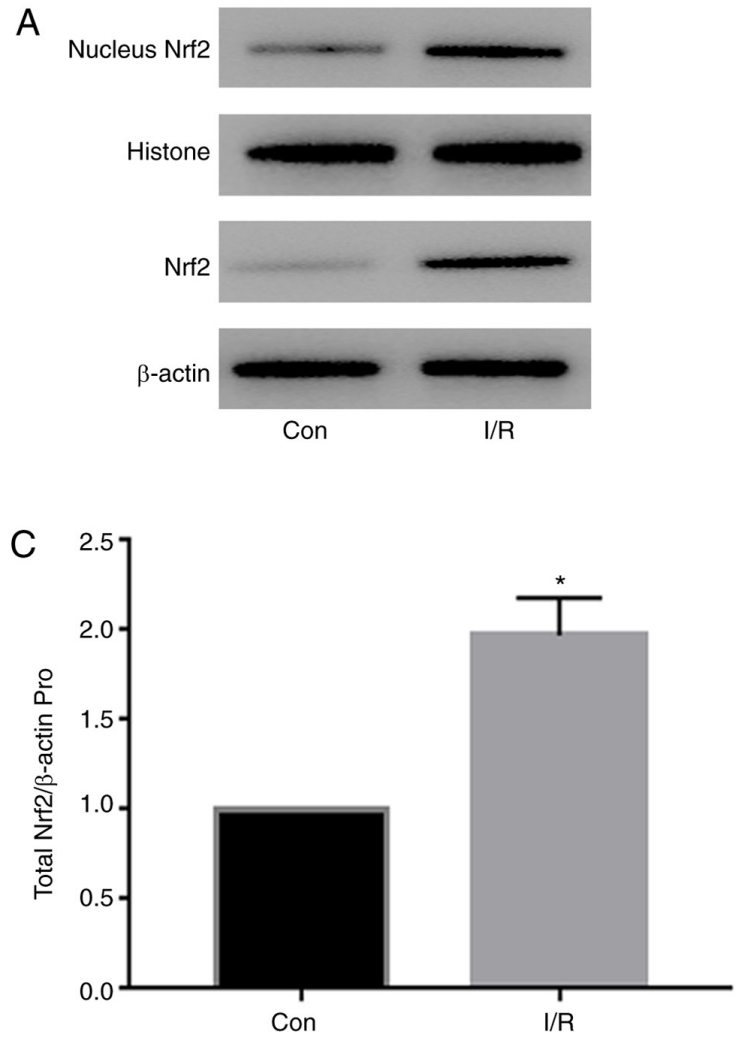

E

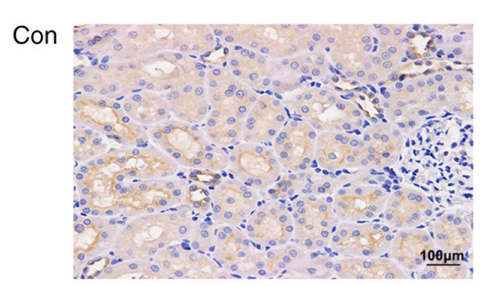

l/R

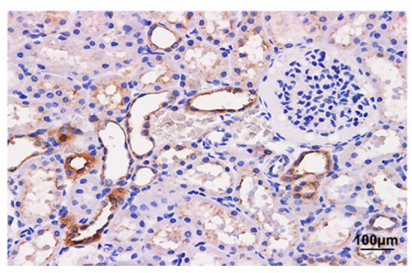

B

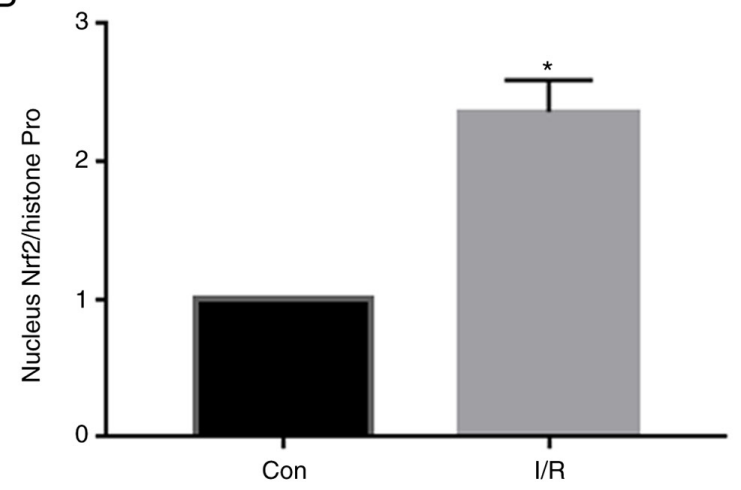

$\mathrm{D}$

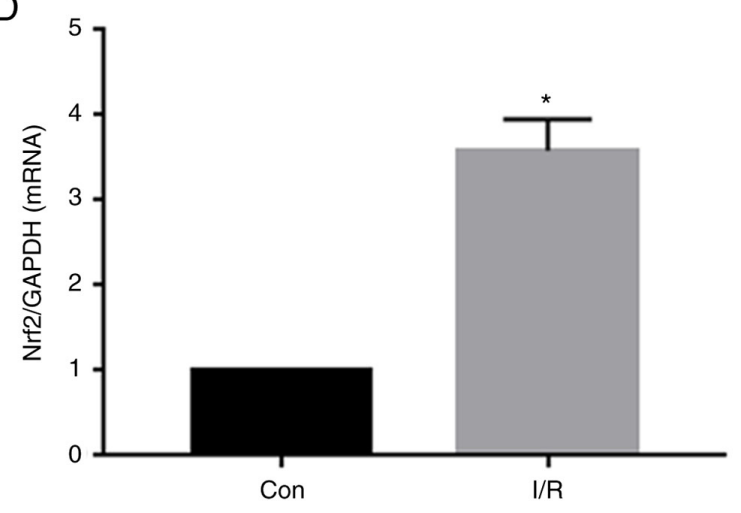

F

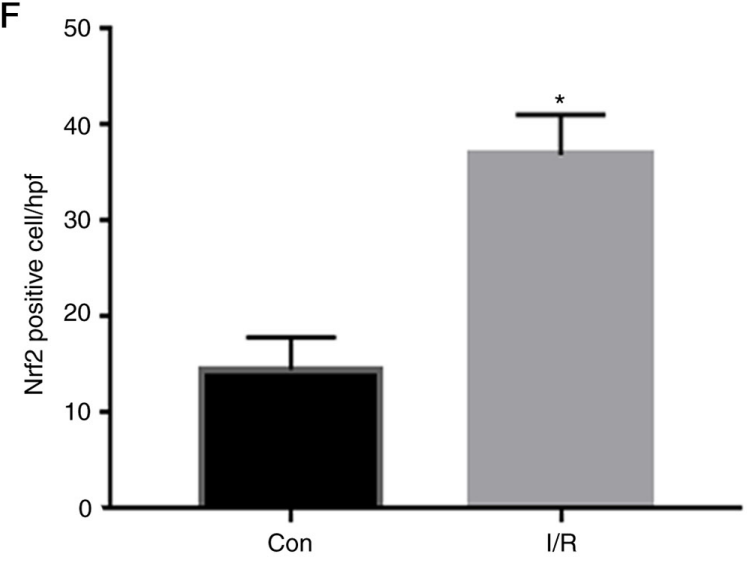

Figure 4. Nrf2 expression levels are upregulated following renal I/R. Mice underwent surgery to induce renal I/R via clamping of the bilateral renal pedicles. At $24 \mathrm{~h}$ post-reperfusion, renal tissue was collected for (A) western blot analysis of (B) nucleic, (C) total protein and mRNA expression levels of Nrf2, (D) reverse transcription-quantitative PCR and (E and F) immunohistochemistry. Scale bar, $100 \mu \mathrm{m}$. Data are presented as the mean $\pm \mathrm{SD}(\mathrm{n}=3)$. ${ }^{*} \mathrm{P}<0.05$ vs. Con. I/R, ischemia/reperfusion; Con, control.

of Nrf2 and NLRP3 inflammasome-associated proteins in wild-type and $\mathrm{KO}$ mice. In wild-type mice, compared with the Con group, the expression levels of Nrf2, NLRP3, caspase-1 and IL-1 $\beta$ were upregulated by renal I/R injury. In addition, NaHS treatment further upregulated Nrf2 expression and downregulated NLRP3, caspase-1 and IL-1 $\beta$ expression levels in the I/R+NaHS group compared with the I/R group (Fig. 6A-E). In Nrf2-KO mice, no statistically significant differences were observed in Nrf2, NLRP3, caspase-1 and IL-1 $\beta$ expression levels between the I/R and I/R+NaHS groups (Fig. 6A-E). In the I/R+NaHS group, Nrf2 expression levels were significantly downregulated, whereas NLRP3, caspase-1 and IL-1 $\beta$ expression levels were significantly upregulated in Nrf2-KO mice compared with wild-type mice. These results suggested that NaHS may decrease NLRP3 inflammasome activation via the Nrf2 signaling pathway in renal I/R injury.

NaHS alleviates renal injury, inflammation and apoptosis via the Nrf2 signaling pathway in renal I/R model mice. NaHS serves an important role in renal damage in AKI, I/R and other disease models (31). NaHS alleviated renal I/R-induced histopathological damage, which was demonstrated by decreased tubular epithelial swelling, tubular dilation and interstitial edema and kidney histological scores in the I/R+NaHS group compared with the I/R group in wild-type mice (Fig. 7A and B). Indicators of renal function, including creatinine, BUN and KIM-1, were also decreased by NaHS treatment in the $\mathrm{I} / \mathrm{R}+\mathrm{NaHS}$ group compared with the I/R group in wild-type 
A
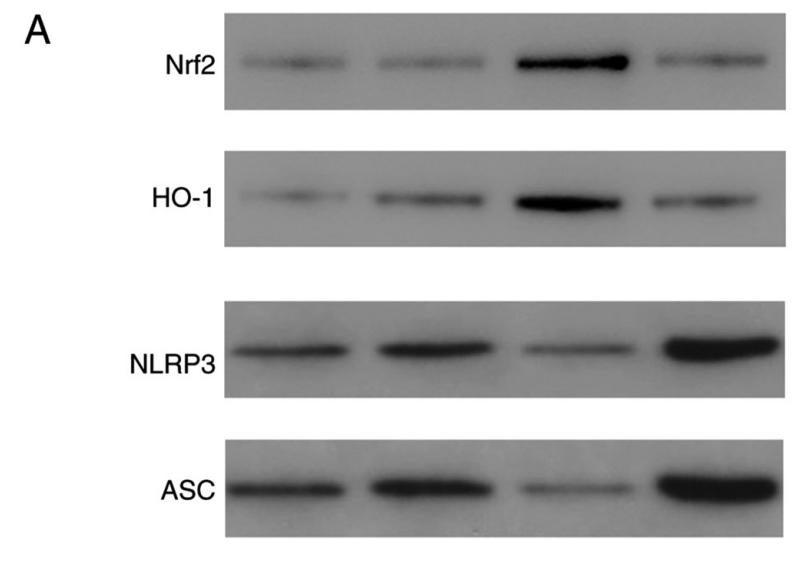

Caspase-1 P10
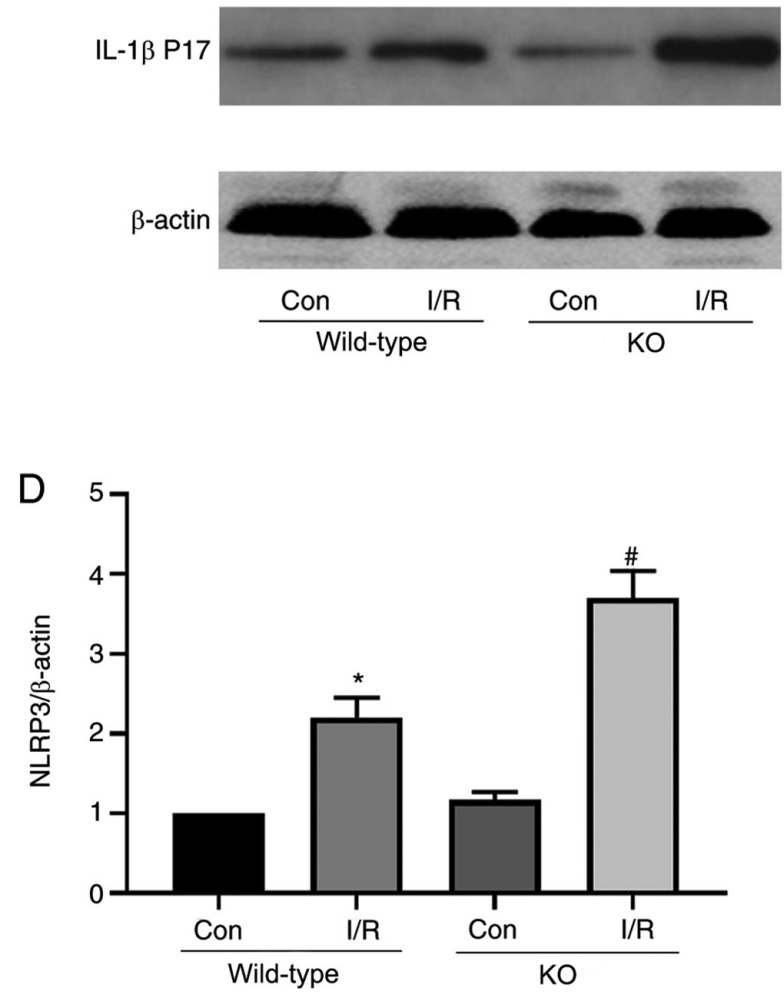

F

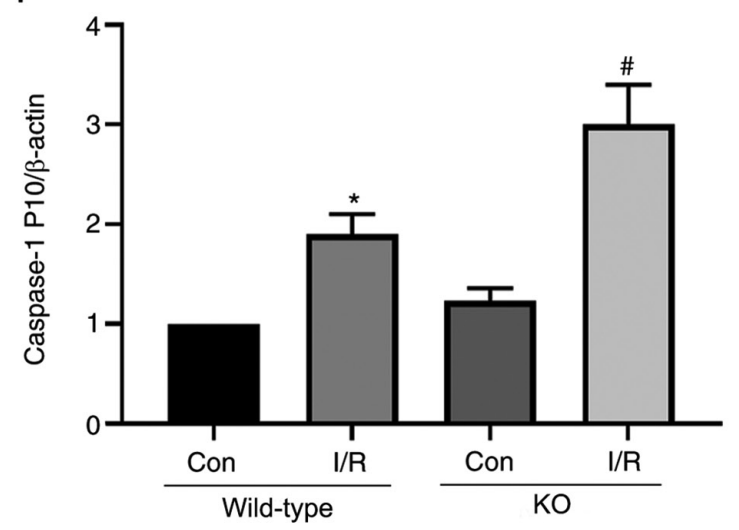

B

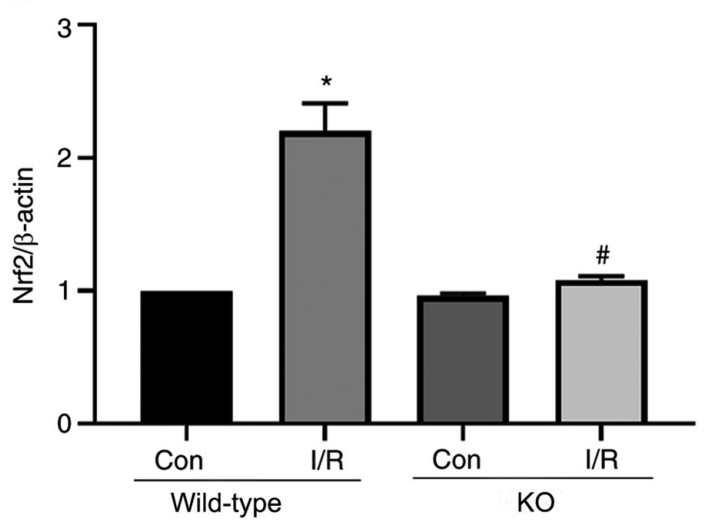

C

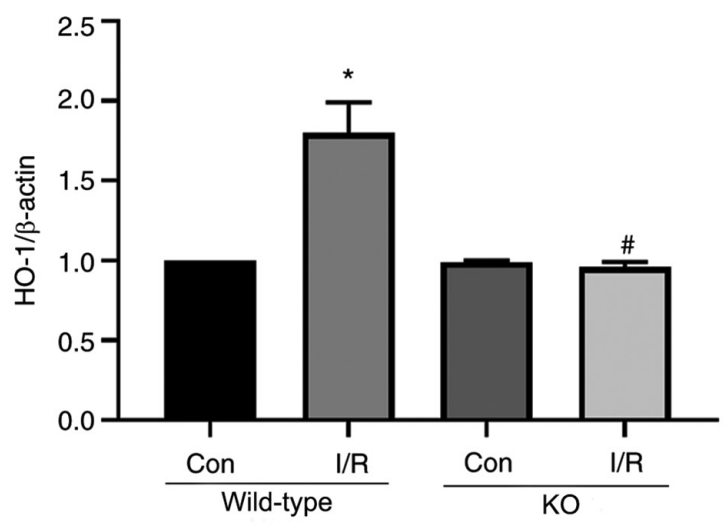

E

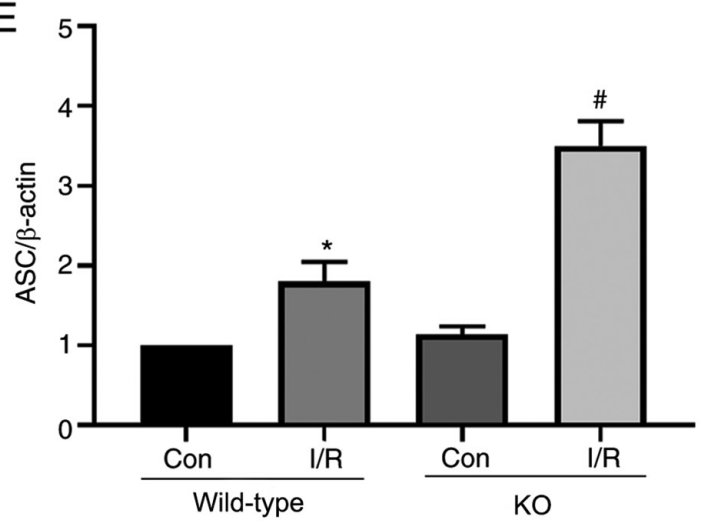

G

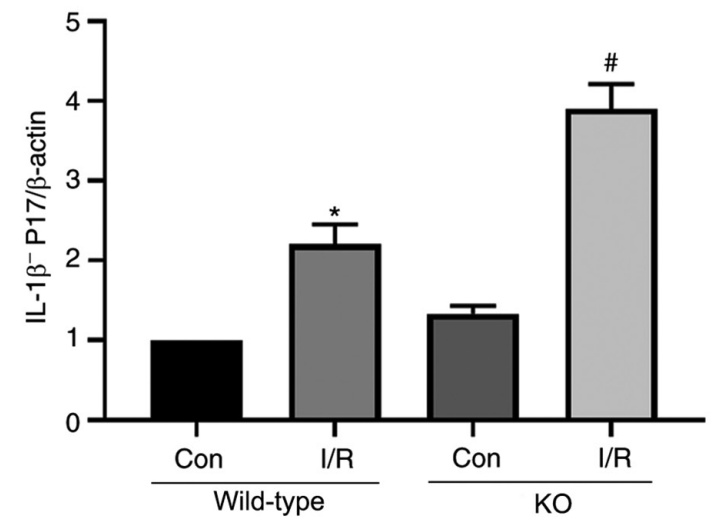

Figure 5. Nrf2 regulates the inhibition of NLRP3 inflammasome activity. Wild-type and Nrf2-KO mice underwent surgery to induce renal I/R via clamping of the bilateral renal pedicles. (A) At $24 \mathrm{~h}$ post-reperfusion, renal tissue was collected for western blot analysis of (B) Nrf2, (C) HO-1, (D) NLRP3, (E) ASC, (F) caspase-1 and (G) IL-1 $\beta$ protein expression levels. Data are presented as the mean $\pm \mathrm{SD}(\mathrm{n}=3)$. ${ }^{*} \mathrm{P}<0.05$ vs. Con wild-type mice; ${ }^{*} \mathrm{P}<0.05$ vs. I/R wild-type mice. NLRP3, NLR family pyrin domain containing 3; ASC, PYD and CARD domain containing; HO-1, heme oxygenase 1; KO, knockout; Con, control; $\mathrm{I} / \mathrm{R}$, ischemia/reperfusion. 
A

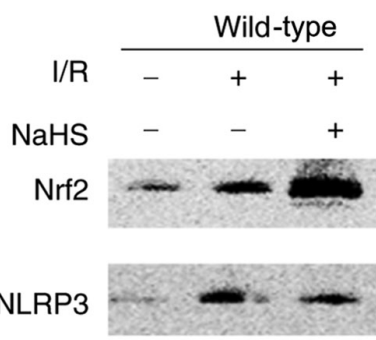

Caspase-1 P10

IL-1 $\beta$ P17

$\beta$-actn

B

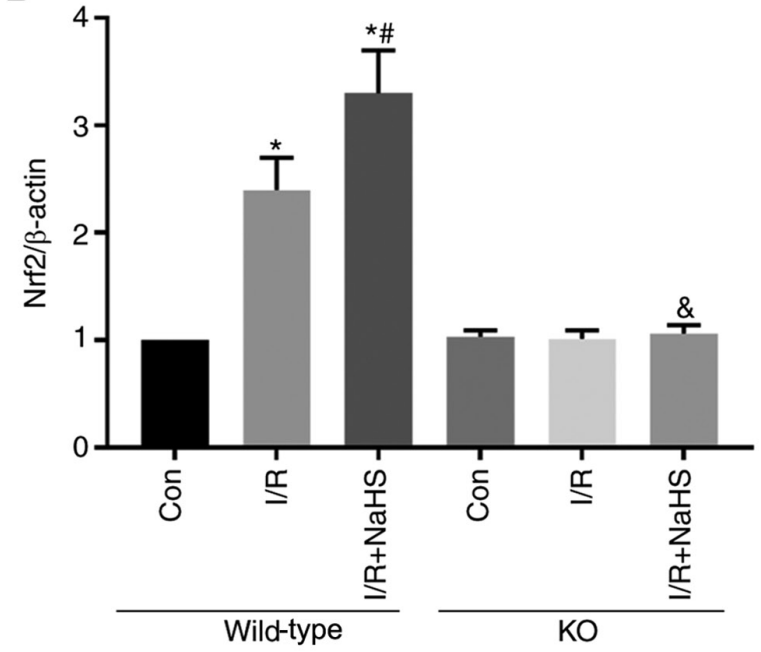

D

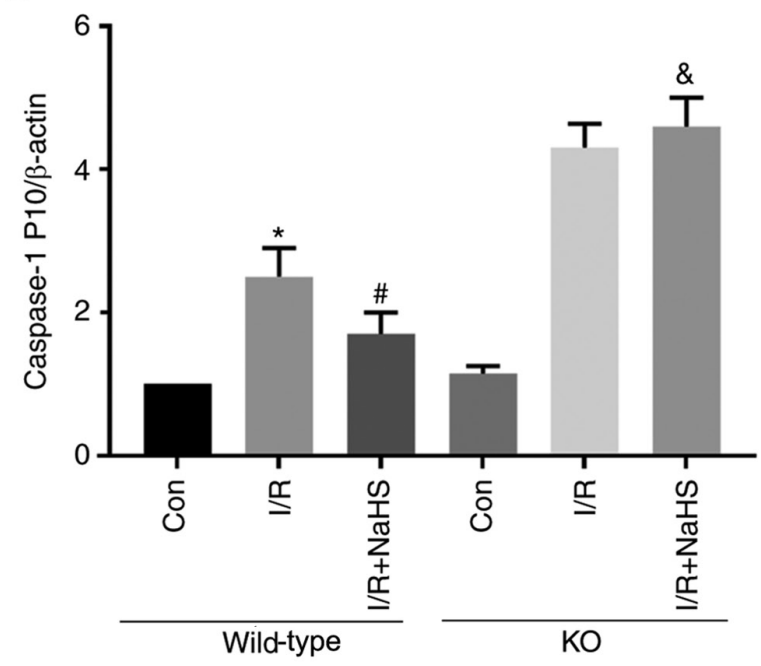

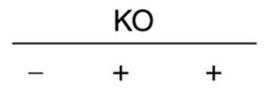
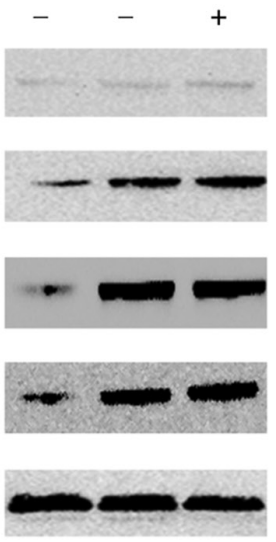

C

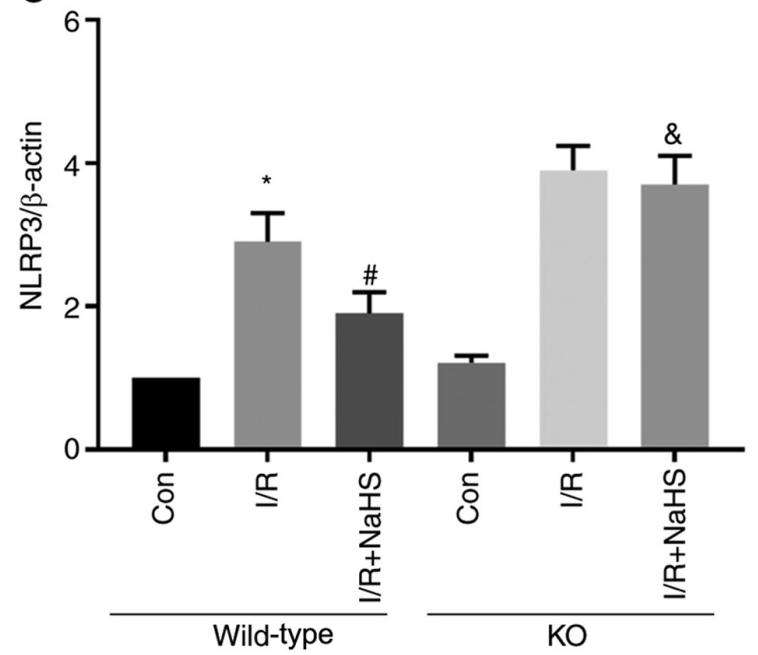

E

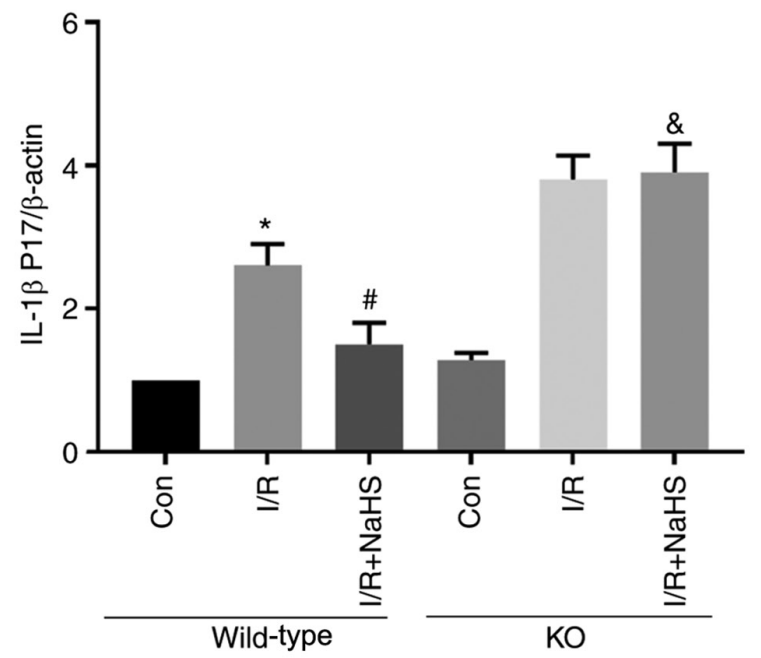

Figure 6. NaHS downregulates I/R-induced upregulation of NLRP3 protein expression levels via the Nrf2 signaling pathway. Wild-type and Nrf2-KO mice underwent surgery to induce renal I/R via clamping of the bilateral renal pedicles. Mice were treated with $50 \mu \mathrm{mol} / \mathrm{kg}$ intraperitoneal NaHS prior to renal ischemia. (A) At $24 \mathrm{~h}$ post-reperfusion, renal tissue was collected for western blot analysis of (B) Nrf2, (C) NLRP3, (D) caspase-1 and (E) IL-1 13 protein expression levels. Data are presented as the mean $\pm \mathrm{SD}(\mathrm{n}=3)$. ${ }^{*} \mathrm{P}<0.05$ vs. Con wild-type mice; ${ }^{\# \mathrm{P}}<0.05$ vs. I/R wild-type mice; ${ }^{\&} \mathrm{P}<0.05$ vs. I/R+NaHS wild-type mice. NaHS, sodium hydrosulfide; I/R, ischemia/reperfusion; NLRP3, NLR family pyrin domain containing 3; KO, knockout; Con, control.

mice (Fig. 7C-E). However, in Nrf2-KO mice, NaHS was unable to decrease the increased kidney histological score and levels of renal function indicators induced by renal I/R.
Furthermore, the percentage of apoptotic cells and release of cytokines, TNF- $\alpha$, IL-1 $\beta$ and IL-6, were all decreased following NaHS treatment in the $\mathrm{I} / \mathrm{R}+\mathrm{NaHS}$ 
A
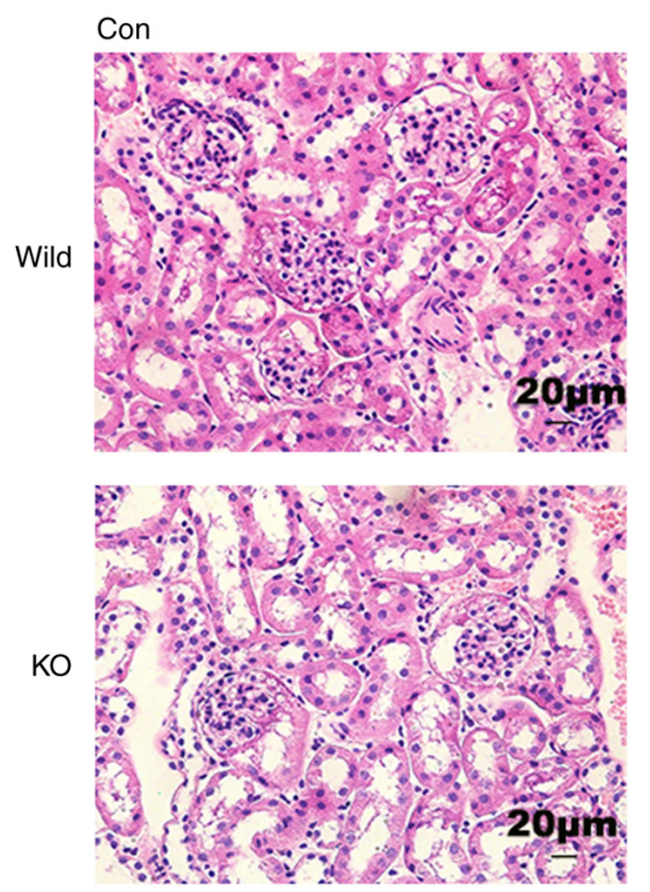

I/R
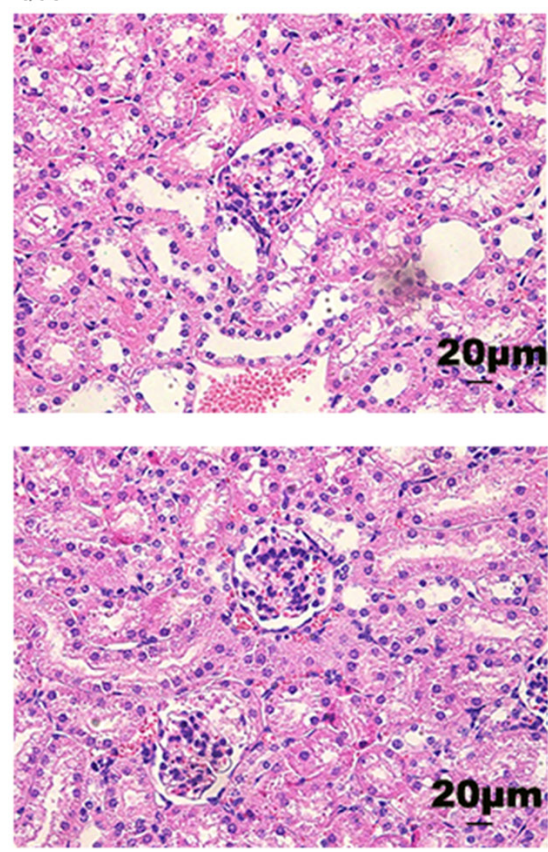

I/R+NaHS
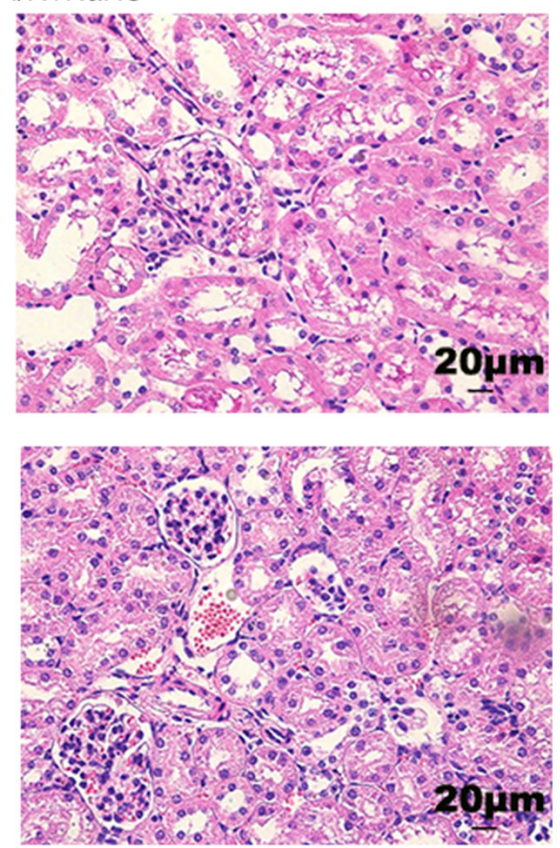

B

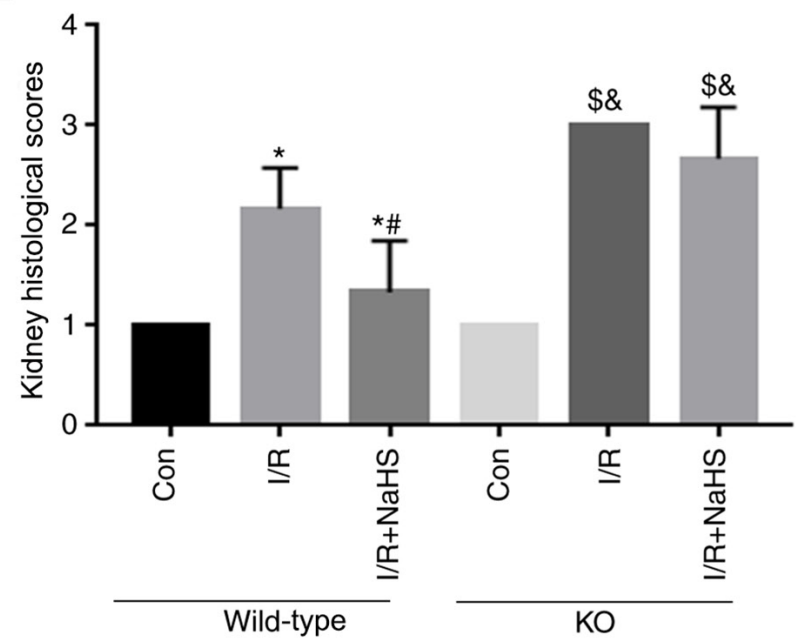

D

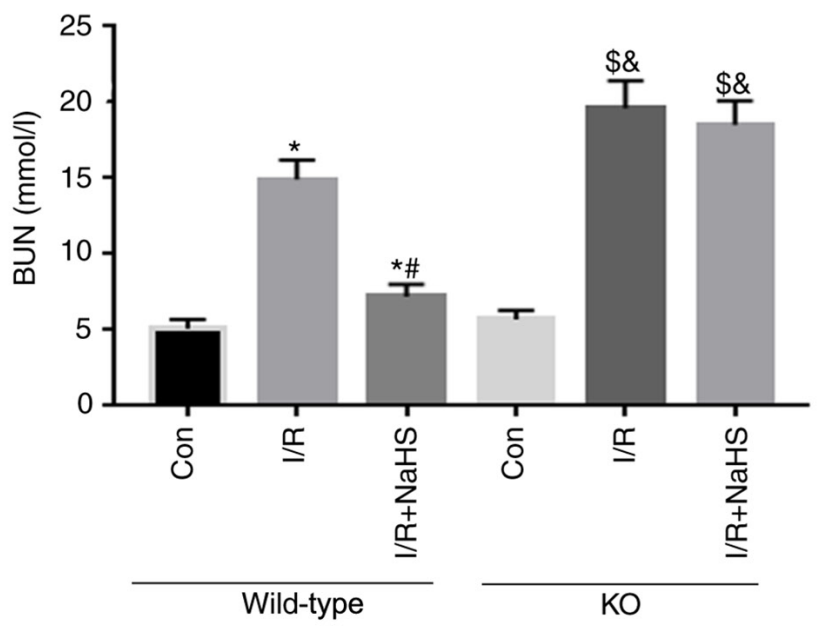

C

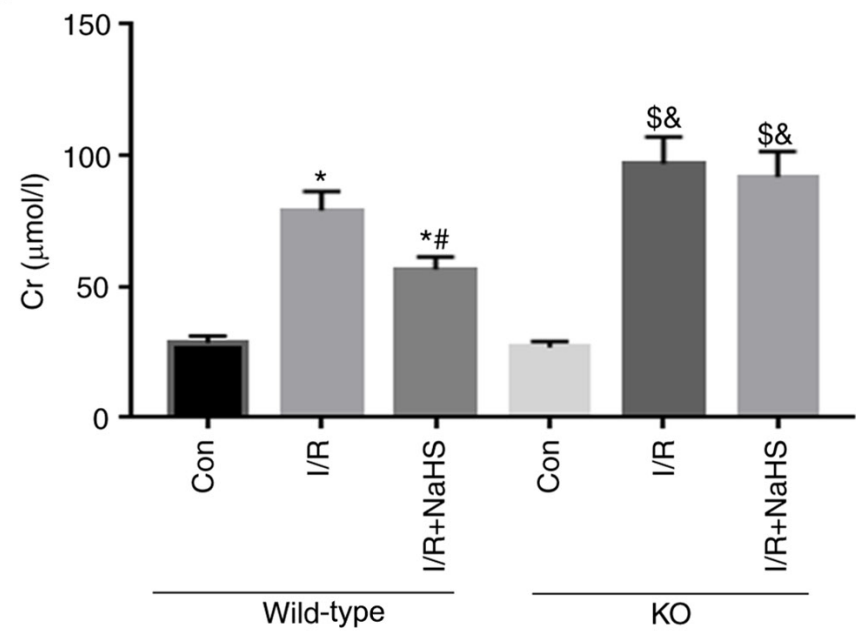

E

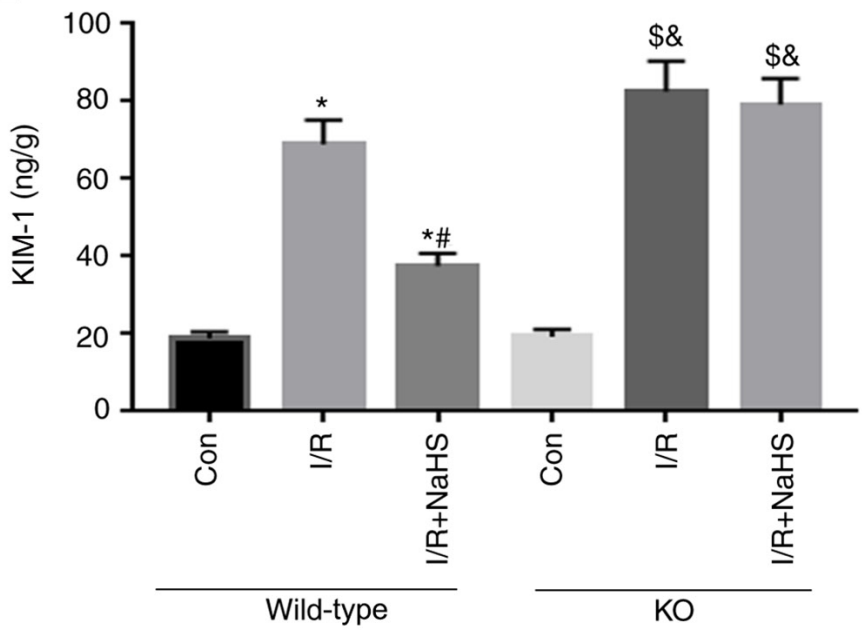

Figure 7. Continued. 
F
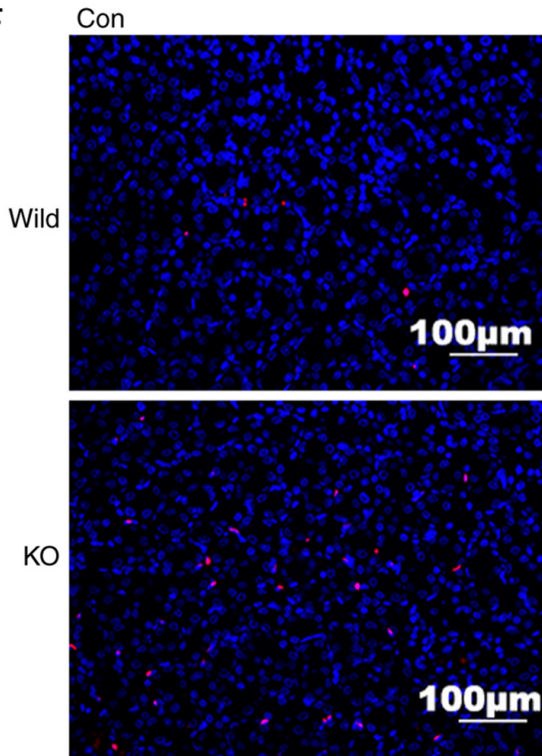

G

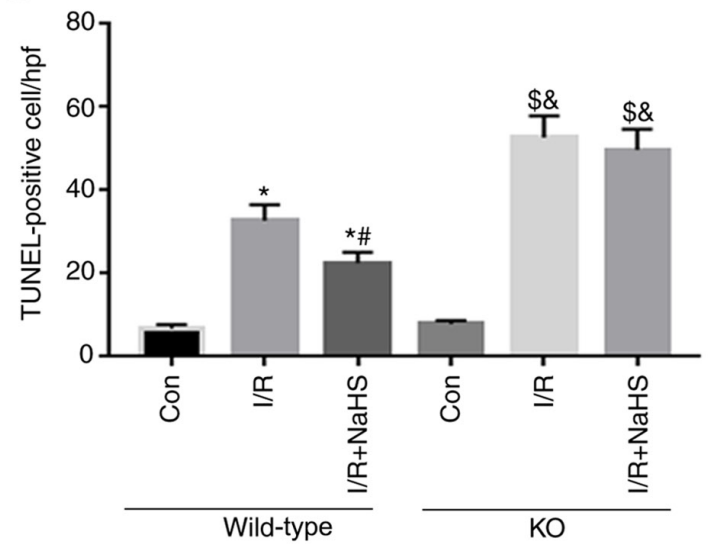

I

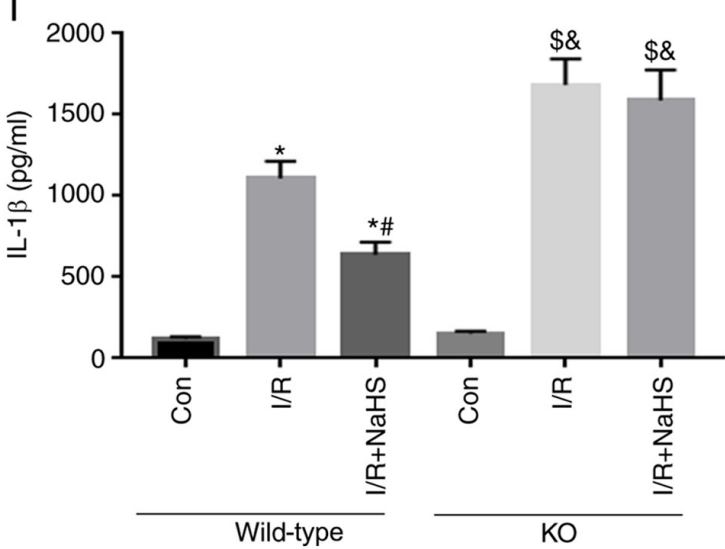

I/R

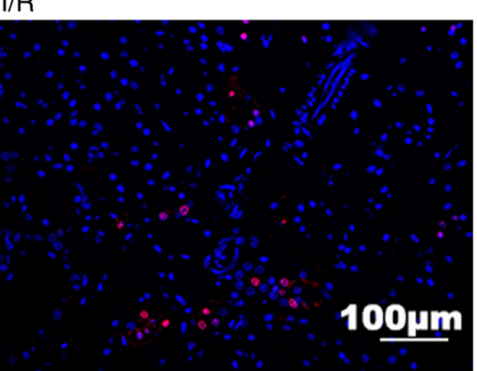

$\mathrm{I} / \mathrm{R}+\mathrm{NaHS}$
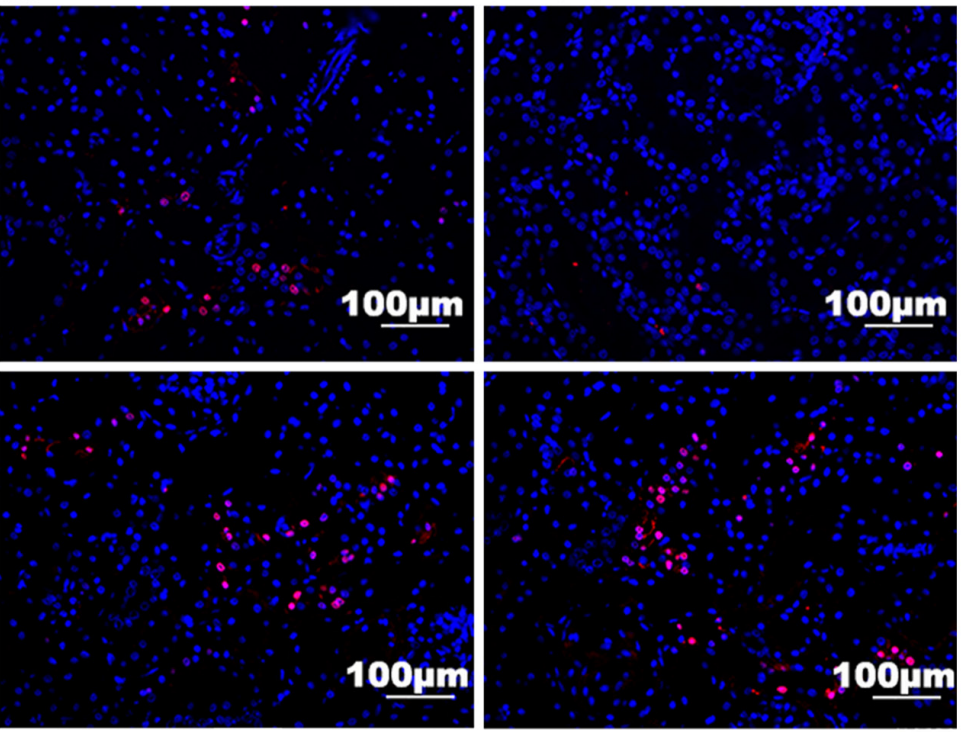

$\mathrm{H}$

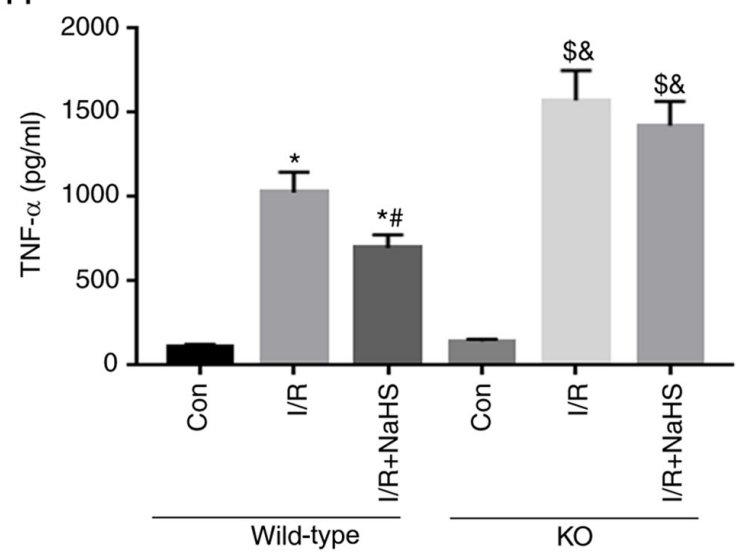

J

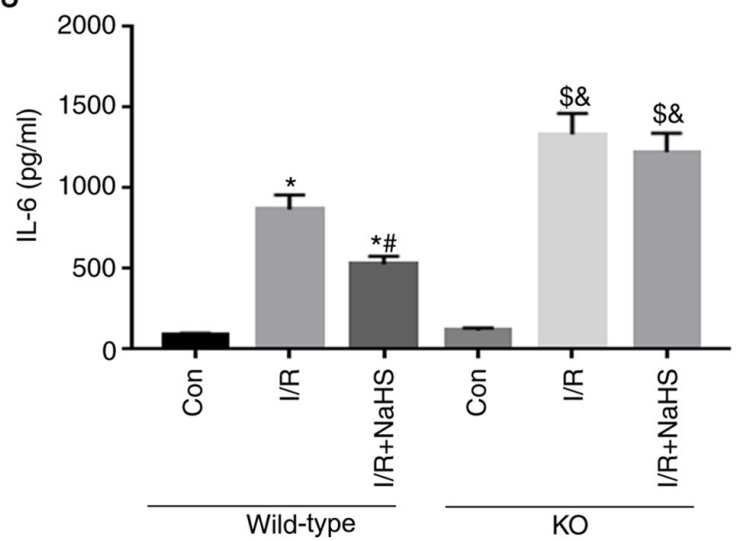

Figure 7. NaHS alleviates renal dysfunction, excessive release of cytokines and cell apoptosis induced by renal I/R via the Nrf2 signaling pathway. Wild-type and Nrf2-KO mice underwent surgery to induce renal I/R via clamping of the bilateral renal pedicles. Mice were treated with $50 \mu$ mol $/ \mathrm{kg}$ intraperitoneal NaHS prior to renal ischemia. (A) At $24 \mathrm{~h}$ post-reperfusion, blood and renal tissue were collected to measure (B) histopathological changes and (C) Cr, (D) BUN and (E) KIM-1 levels. Scale bar, $20 \mu \mathrm{m}$. (F and G) Apoptosis and expression levels of (H) TNF- $\alpha$, (I) IL-1 $\beta$ and (J) IL-6 were assessed. Scale bar, $100 \mu \mathrm{m}$. Data are presented as the mean $\pm \mathrm{SD}(\mathrm{n}=3)$. ${ }^{*} \mathrm{P}<0.05$ vs. Con wild-type mice; ${ }^{*} \mathrm{P}<0.05$ vs. I/R wild-type mice; ${ }^{\star} \mathrm{P}<0.05$ vs. I/R+NaHS wild-type mice; ${ }^{\$} \mathrm{P}<0.05$ vs. Con KO mice. NaHS, sodium hydrosulfide; I/R, ischemia/reperfusion; KO, knockout; BUN, blood urea nitrogen; KIM-1, kidney injury molecule-1; Con, control; Cr, creatinine.

group compared with the $\mathrm{I} / \mathrm{R}$ group in wild-type mice (Fig. 7F-J). However, NaHS was unable to exert a protective effect against apoptosis and excessive release of inflammatory factors following reperfusion of renal tissue in the I/R+NaHS group of Nrf2-KO mice compared with I/R+NaHS wild-type mice (Fig. 7F-J). These results 
suggested that NaHS may alleviate renal injury, inflammation and apoptosis in renal I/R wild-type mice, but not in Nrf2-KO mice.

\section{Discussion}

Inflammation is a key pathogenic processes of AKI induced by I/R (4). The NLRP3 inflammasome and Nrf2 signaling pathway participate in the regulation of inflammation in kidney injury (32). The present study found that AKI induced by I/R activated the NLRP3 inflammasome and its adaptor, ASC, promoted the maturation of pro-caspase- 1 and pro-IL-1 $\beta$ and accelerated the excessive release of cytokines and apoptosis, which culminated in severe renal dysfunction. Inhibition of the NLRP3 inflammasome by MCC950 treatment improved renal function, levels of inflammation and apoptosis in renal tissue. In addition to activating NLRP3, renal I/R also activated the Nrf2 signaling pathway. However, the absence of Nrf2 in Nrf2-KO mice led to further upregulation of the NLRP3 inflammasome and its adaptor. NaHS treatment was found to alleviate NLRP3 inflammasome activity via the Nrf2 signaling pathway. Moreover, renal injury, inflammation and apoptosis were decreased by NaHS treatment via Nrf2-mediated inhibition of NLRP3 inflammasome activation.

Renal I/R injury is an important clinical problem and primary cause of AKI, which leads to increased risk of developing chronic kidney disease (33). Inflammation is an important pathological feature of ischemic injury and occurs as a consequence of immune cell activation via recognition of pathogen- and damage-associated molecular patterns (34). Moreover, it was previously reported that the NLRP3 inflammasome serves a role in a range of kidney diseases by regulating inflammation, pyroptosis, apoptosis and fibrosis (35). The NLRP3 inflammasome is a protein complex comprising NLRP3, its adapter protein, ASC, and caspase-1. Caspase-1 cleaves pro-IL-1 $\beta$ and pro-IL-18 into mature, activated secretory forms. Renal injury induced by different pathologies, including ischemia (33), activates the inflammasome complex, upregulates NLRP3 expression and promotes the subsequent maturation of pro-IL-1 $\beta$ (36). NLRP3 KO using small interfering RNA in mice or renal tubular epithelial cells exerts a protective effect against renal tissue injury induced by ischemia or cell injury in the absence of glucose (37). The present results indicated that renal I/R induced activation of the NLRP3 inflammasome, while inhibition of NLRP3 using MCC950 significantly downregulated NLRP3 and ASC expression levels and the maturation of pro-caspase- 1 and pro-IL-1 $\beta$ in the renal I/R injury model. In addition, NLRP3 inhibition by MCC950 ameliorated renal dysfunction, and decreased histopathological injury and score, excessive release of cytokines and the number of apoptotic cells. These data suggested that NLRP3 activation may serve a key role in renal injury and inhibition of NLRP3 may exert a protective effect against tissue injury and dysfunction induced by renal I/R.

Previous studies have reported that Nrf2 participates in the inflammatory response (10-12). In addition, Nrf2 serves a key anti-inflammatory, anti-oxidative or anti-apoptotic role in ischemic conditions. Nrf2/antioxidant response element signaling pathway activation attenuates inflammation and apoptosis in renal tissue of cyclophosphamide-induced mice (38). Another study demonstrated that Nrf2 activation by sulforaphane inhibits NF- $\kappa B$ signaling pathway activity, thereby relieving inflammation in dystrophic muscle tissue (39). Furthermore, the knockdown of Nrf2 promotes NLRP3 inflammasome activation and leads to IL-1 $\beta$ activation in an ischemia model (11). The present data supported the findings that renal I/R may induce the Nrf2 signaling pathway and expression of its downstream target genes, such as HO-1. Nrf2-KO mice further promoted activation of the NLRP3 inflammasome, which indicated that NLRP3, ASC, caspase- 1 and IL-1 $\beta$ expression levels were increased in the renal I/R model. These results suggested that Nrf2 exerted an inhibitory effect on NLRP3 inflammasome activation in renal I/R injury.

Previous research has reported that the kidney produces $\mathrm{H}_{2} \mathrm{~S}$ (40). Furthermore, $\mathrm{H}_{2} \mathrm{~S}$ increases renal blood flow and promotes the clearance function of the kidney, as demonstrated by elevated glomerular filtration rate (41). Moreover, $\mathrm{H}_{2} \mathrm{~S}$ not only alleviates inflammation and oxidative stress, but also serves a crucial role in regulating endothelial dysfunction and hypertension (28). $\mathrm{H}_{2} \mathrm{~S}$ participates in the regulation of renal-associated disease, such as I/R injury and obstructive and diabetic nephropathy (42), however, the underlying mechanisms remain poorly understood. NaHS has been used as a $\mathrm{H}_{2} \mathrm{~S}$ exogenous donor in research (43). In the present study, the delivery of $\mathrm{H}_{2} \mathrm{~S}$ was in the form of NaHS. The present results demonstrated that NaHS ameliorated tissue injury, kidney dysfunction, excessive release of cytokines and apoptosis induced by renal I/R. It was previously reported that NaHS prevents microglial activation and inflammation induced by nerve injury via regulating the Nrf2 signaling pathway (44). Consistent with the hypothesis that NaHS regulates inflammation via the Nrf2 signaling pathway, the present results demonstrated that NaHS upregulated Nrf2 expression levels and inhibited expression levels of NLRP3 in renal I/R model mice. Furthermore, Nrf2 KO abolished the regulatory effects of NaHS on Nrf2 and the NLRP3 inflammasome. The present study also investigated the role of Nrf2 on renal injury and function following NaHS treatment; inhibition of Nrf2 not only partially reversed the protective effect of NaHS on kidney injury and dysfunction, but also reversed the inhibitory effect of NaHS on the inflammatory response and apoptosis following renal I/R. These results suggested that Nrf2 may be required for the protective effect of NaHS on AKI induced by I/R, and NaHS may exert its protective role against tissue injury via Nrf2-mediated NLPR 3 inflammasome inhibition.

In conclusion, I/R-induced renal injury activated the NLRP3 inflammasome and Nrf2 signaling pathway, and inhibition of the NLRP3 inflammasome protected against renal injury. Nrf2 negatively regulated NLRP3 inflammasome activation and NaHS alleviated kidney injury and dysfunction, apoptosis and the inflammatory response via Nrf2-mediated NLRP3 inflammasome inhibition. These results provide novel insight into a potential future target for the treatment of renal ischemic injury.

\section{Acknowledgements}

Not applicable. 


\section{Funding}

No funding was received.

\section{Availability of data and materials}

The datasets used and/or analyzed in the present study are available from the corresponding author on reasonable request.

\section{Authors' contributions}

ML and $\mathrm{HC}$ designed the research and wrote the manuscript. YS and HC constructed the animal model. YW performed sample collection and experiments. YS and ML analyzed the data. YS, ML and HC confirm the authenticity of all the raw data. All authors read and approved the final manuscript.

\section{Ethics approval and consent to participate}

All animal protocols were approved by the Animal Care and Use Committee of General Hospital of Tianjin Medical University (approval no. IRB2020-DW-04; Tianjin, China).

\section{Patient consent for publication}

Not applicable.

\section{Competing interests}

The authors declare that they have no competing interests.

\section{References}

1. Park J, Lee EG, Yi HJ, Kim NH, Rhee SG and Woo HA: Ablation of peroxiredoxin $\mathrm{V}$ exacerbates Ischemia/Reperfusion-Induced kidney injury in mice. Antioxidants (Basel) 9: 769, 2020.

2. Ghasemzadeh P, Rezayat SM, Adeli S and Rahbar-Roshandel N: Protective effect of $25 \mathrm{Mg}$-porphyrin-fullerene nanoparticles on oxygen-glucose deprivation/reperfusion injury in PC12 cells Acta Med Iran 54: 478-484, 2016

3. Schroder K and Tschopp J: The inflammasomes. Cell 140: 821-832, 2010

4. Tang TT, Lv LL, Pan MM, Wen Y, Wang B, Li ZL, Wu M, Wang FM, Crowley SD and Liu BC: Hydroxychloroquine attenuates renal ischemia/reperfusion injury by inhibiting cathepsin mediated NLRP3 inflammasome activation. Cell Death Dis 9: 351, 2018.

5. Nazir S, Gadi I, Al-Dabet MM, Elwakiel A, Kohli S, Ghosh S, Manoharan J, Ranjan S, Bock F, Braun-Dullaeus RC, et al: Cytoprotective activated protein $\mathrm{C}$ averts Nlrp3 inflammasome-induced ischemia-reperfusion injury via mTORC1 inhibition. Blood 130: 2664-2677, 2017.

6. Iyer SS, Pulskens WP, Sadler JJ, Butter LM, Teske GJ, Ulland TK, Eisenbarth SC, Florquin S, Flavell RA, Leemans JC and Sutterwala FS: Necrotic cells trigger a sterile inflammatory response through the Nlrp3 inflammasome. Proc Natl Acad Sci USA 106: 20388-20393, 2009.

7. Cao Y, Fei D, Chen M, Sun M, Xu J, Kang K, Jiang L and Zhao M: Role of the nucleotide-binding domain-like receptor protein 3 inflammasome in acute kidney injury. FEBS J 282: 3799-3807, 2015.

8. Wang W, Faubel S, Ljubanovic D, Mitra A, Falk SA, Kim J, Tao Y, Soloviev A, Reznikov LL, Dinarello CA, et al: Endotoxemic acute renal failure is attenuated in caspase-1-deficient mice. Am J Physiol Renal Physiol 288: F997-F1004, 2005.

9. Liu Q, Gao Y and Ci X: Role of Nrf2 and its activators in respiratory diseases. Oxid Med Cell Longev 2019: 7090534, 2019.

10. Shelton LM, Park BK and Copple IM: Role of Nrf2 in protection against acute kidney injury. Kidney Int 84: 1090-1095, 2013.
11. Xu X, Zhang L, Ye X, Hao Q, Zhang T, Cui G and Yu M: Nrf2/ARE pathway inhibits ROS-induced NLRP3 inflammasome activation in BV2 cells after cerebral ischemia reperfusion. Inflamm Res 67: 57-65, 2018.

12. Hou Y, Wang Y, He Q, Li L, Xie H, Zhao Y and Zhao J: Nrf2 inhibits NLRP3 inflammasome activation through regulating Trx1/TXNIP complex in cerebral ischemia reperfusion injury. Behav Brain Res 336: 32-39, 2018.

13. Yang $\mathrm{H}, \mathrm{Lv} \mathrm{H}, \mathrm{Li} \mathrm{H}, \mathrm{Ci} \mathrm{X}$ and Peng L: Oridonin protects LPS-induced acute lung injury by modulating Nrf2-mediated oxidative stress and Nrf2-independent NLRP3 and NF- $\kappa \mathrm{B}$ pathways. Cell Commun Signal 17: 62, 2019.

14. Wu D, Wang H, Teng T, Duan S, Ji A and Li Y: Hydrogen sulfide and autophagy: A double edged sword. Pharmacol Res 131: 120-127, 2018.

15. Hu LF, Lu M, Wu ZY, Wong PT and Bian JS: Hydrogen sulfide inhibits rotenone-induced apoptosis via preservation of mitochondrial function. Mol Pharmacol 75: 27-34, 2009.

16. Jha S, Calvert JW, Duranski MR, Ramachandran A and Lefer DJ: Hydrogen sulfide attenuates hepatic ischemia-reperfusion injury: Role of antioxidant and antiapoptotic signaling. Am J Physiol Heart Circ Physiol 295: H801-H806, 2008.

17. Mariggio MA, Minunno V, Riccardi S, Santacroce R, De Rinaldis P and Fumarulo R: Sulfide enhancement of PMN apoptosis. Immunopharmacol Immunotoxicol 20: 399-408, 1998.

18. Sivarajah A, Collino M, Yasin M, Benetti E, Gallicchio M, Mazzon E, Cuzzocrea S, Fantozzi R and Thiemermann C: Anti-apoptotic and anti-inflammatory effects of hydrogen sulfide in a rat model of regional myocardial I/R. Shock 31: 267-274, 2009.

19. Whiteman M, Armstrong JS, Chu SH, Jia-Ling S, Wong BS, Cheung NS, Halliwell B and Moore PK: The novel neuromodulator hydrogen sulfide: An endogenous peroxynitrite 'scavenger'? J Neurochem 90: 765-768, 2004.

20. Zanardo RC, Brancaleone V, Distrutti E, Fiorucci S, Cirino G and Wallace JL: Hydrogen sulfide is an endogenous modulator of leukocyte-mediated inflammation. FASEB J 20: 2118-2120, 2006.

21. Bai YD, Yang YR, Mu XP, Lin G, Wang YP, Jin S, Chen Y, Wang MJ and Zhu YC: Hydrogen sulfide alleviates acute myocardial ischemia injury by modulating autophagy and inflammation response under oxidative stress. Oxid Med Cell Longev 2018: 3402809, 2018

22. Li S, Lin Q, Shao X, Mou S, Gu L, Wang L, Zhang Z, Shen J, Zhou Y, Qi C, et al: NLRP3 inflammasome inhibition attenuates cisplatin-induced renal fibrosis by decreasing oxidative stress and inflammation. Exp Cell Res 383: 111488, 2019.

23. Livak KJ and Schmittgen TD: Analysis of relative gene expression data using real-time quantitative PCR and the 2(-Delta Delta C(T)) method. Methods 25: 402-408, 2001.

24. Shingu C, Koga H, Hagiwara S, Matsumoto S, Goto K, Yokoi I and Noguchi T: Hydrogen-rich saline solution attenuates renal ischemia-reperfusion injury. J Anesth 24: 569-574, 2010.

25. Vilaysane A, Chun J, Seamone ME, Wang W, Chin R, Hirota S, Li Y, Clark SA, Tschopp J, Trpkov K, et al: The NLRP3 inflammasome promotes renal inflammation and contributes to CKD. J Am Soc Nephrol 21: 1732-1744, 2010.

26. Yuan X, Wang X, Chen C, Zhou J and Han M: Bone mesenchymal stem cells ameliorate ischemia/reperfusion-induced damage in renal epithelial cells via microRNA-223. Stem Cell Res Ther 8: 146, 2017.

27. Kalbolandi SM, Gorji AV,Babaahmadi-Rezaei H and Mansouri E: Luteolin confers renoprotection against ischemia-reperfusion injury via involving Nrf2 pathway and regulating miR320. Mol Biol Rep 46: 4039-4047, 2019.

28. Li J, Teng X, Jin S, Dong J, Guo Q, Tian D and Wu Y: Hydrogen sulfide improves endothelial dysfunction by inhibiting the vicious cycle of NLRP3 inflammasome and oxidative stress in spontaneously hypertensive rats. J Hypertens 37: 1633-1643, 2019.

29. Li F, Zhang P, Zhang M, Liang L, Sun X, Li M, Tang Y, Bao A Gong J, Zhang J, et al: Hydrogen sulfide prevents and partially reverses ozone-induced features of lung inflammation and emphysema in mice. Am J Respir Cell Mol Biol 55: 72-81, 2016.

30. Xie L, Gu Y, Wen M, Zhao S, Wang W, Ma Y, Meng G, Han Y, Wang Y, Liu G, et al: Hydrogen sulfide induces Keap1 S-sulfhydration and suppresses diabetes-accelerated atherosclerosis via Nrf2 activation. Diabetes 65: 3171-3184, 2016. 
31. Ling Q, Yu X, Wang T, Wang SG, Ye ZQ and Liu JH: Roles of the exogenous H2S-Mediated SR-A signaling pathway in renal ischemia/reperfusion injury in regulating endoplasmic reticulum stress-induced autophagy in a rat model. Cell Physiol Biochem 41: 2461-2474, 2017.

32. Yifan Z, Benxiang N, Zheng X, Luwei X, Liuhua Z, Yuzheng G and Ruipeng J: Ceftriaxone calcium crystals induce acute kidney injury by NLRP3-mediated inflammation and oxidative stress injury. Oxid Med Cell Longev 2020: 6428498, 2020.

33. Asvapromtada S, Sonoda H, Kinouchi M, Oshikawa S, Takahashi S, Hoshino Y, Sinlapadeelerdkul T, Yokota-Ikeda N, Matsuzaki T and Ikeda M: Characterization of urinary exosomal release of aquaporin-1 and -2 after renal ischemia-reperfusion in rats. Am J Physiol Renal Physiol 314: F584-F601, 2018.

34. Wu J, Han M, Li J, Yang X, Zhen X, Schlaak JF, Yang D and Lu M: Pattern recognition receptors and liver failure. Crit Rev Immunol 39: 289-311, 2019.

35. Fan J, Xie K, Wang L, Zheng N and Yu X: Roles of inflammasomes in inflammatory kidney diseases. Mediators Inflamm 2019: $2923072,2019$.

36. Bakker PJ, Butter LM, Claessen N, Teske GJ, Sutterwala FS, Florquin S and Leemans JC: A tissue-specific role for Nlrp3 in tubular epithelial repair after renal ischemia/reperfusion. Am J Pathol 184: 2013-2022, 2014.

37. Shen J, Wang L, Jiang N, Mou S, Zhang M, Gu L, Shao X, Wang Q, Qi C, Li S, et al: NLRP3 inflammasome mediates contrast media-induced acute kidney injury by regulating cell apoptosis. Sci Rep 6: 34682, 2016.

38. ALHaithloul H, Alotaibi MF, Bin-Jumah M, Elgebaly $\mathrm{H}$ and Mahmoud AM: Olea europaea leaf extract up-regulates Nrf2/ARE/HO-1 signaling and attenuates cyclophosphamide-induced oxidative stress, inflammation and apoptosis in rat kidney. Biomed Pharmacother 111: 676-685, 2019.
39. Sun CC, Li SJ, Yang CL, Xue RL, Xi YY, Wang L, Zhao QL and Li DJ: Sulforaphane attenuates muscle inflammation in dystrophin-deficient mdx mice via NF-E2-related Factor 2 (Nrf2)-mediated Inhibition of NF- $\kappa \mathrm{B}$ signaling pathway. J Biol Chem 290: 17784-17795, 2015.

40. Stipanuk MH and Beck PW: Characterization of the enzymic capacity for cysteine desulphhydration in liver and kidney of the rat. Biochem J 206: 267-277, 1982.

41. Xia M, Chen L, Muh RW, Li PL and Li N: Production and actions of hydrogen sulfide, a novel gaseous bioactive substance, in the kidneys. J Pharmacol Exp Ther 329: 1056-1062, 2009.

42. Cao X and Bian JS: The role of hydrogen sulfide in renal system. Front Pharmacol 7: 385, 2016.

43. Chen HG, Han HZ, Li Y, Yu YH and Xie KL: Hydrogen alleviated organ injury and dysfunction in sepsis: The role of cross-talk between autophagy and endoplasmic reticulum stress: Experimental research. Int Immunopharmacol 78: $106049,2020$.

44. Chen H, Xie K, Chen Y, Wang Y, Wang Y, Lian N, Zhang K and $\mathrm{Yu} \mathrm{Y}$ : Nrf2/HO-1 signaling pathway participated in the protection of hydrogen sulfide on neuropathic pain in rats. Int Immunopharmacol 75: 105746, 2019. International (CC BY-NC-ND 4.0) License. 